

NISTIR 8178

\section{Guia para os Requisitos de Conformidade de Produtos Cosméticos dos Estados Unidos}

Lisa Benson

Karen Reczek

Esta publicação está disponível gratuitamente em: https://doi.org/10.6028/NIST.IR.8178port 


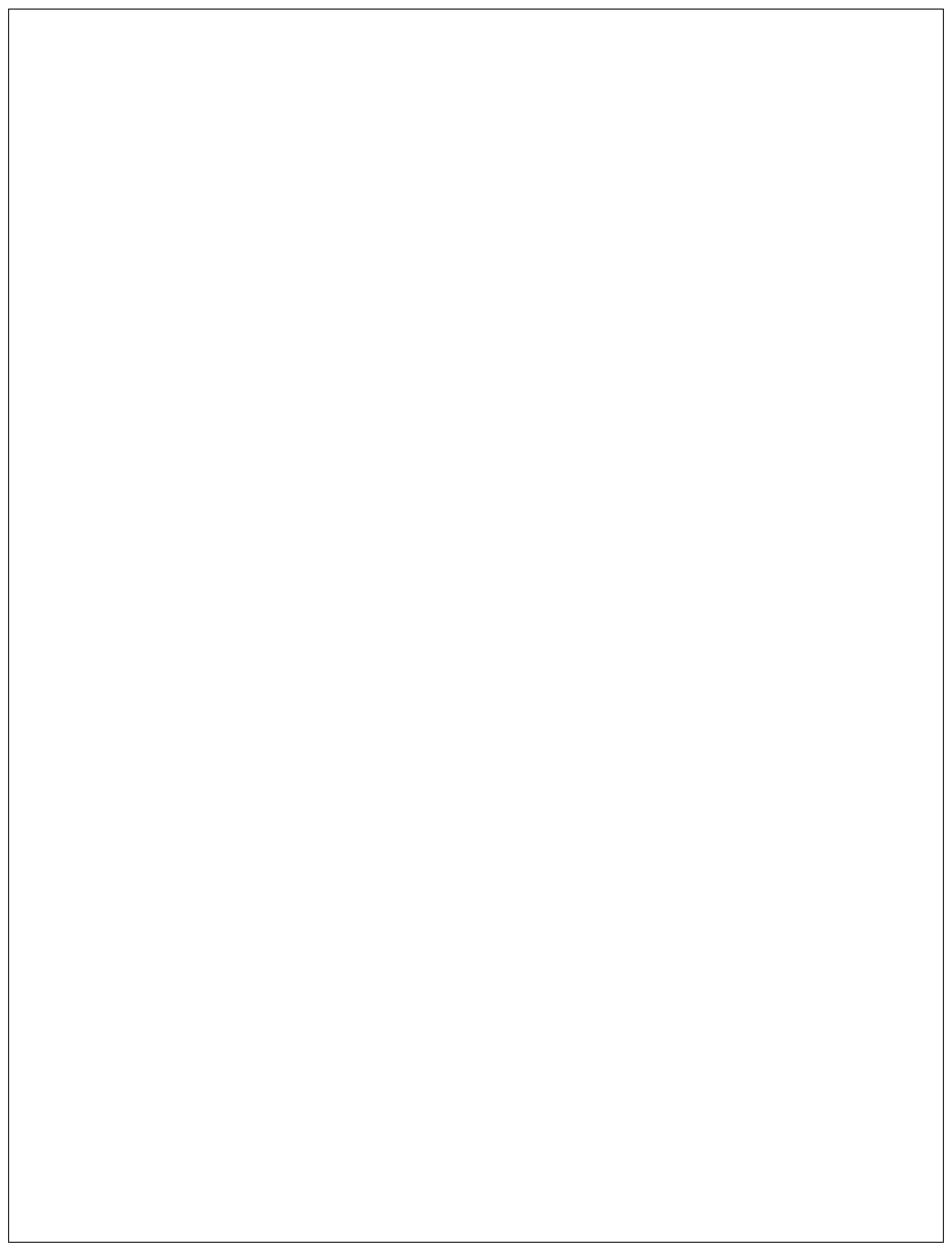


NISTIR 8178

\title{
Guia para os Requisitos de Conformidade de Produtos Cosméticos dos Estados Unidos
}

\author{
Lisa M. Benson* \\ Karen Reczek \\ Escritório de Coordenação de Padrões
}

* Dakota Consulting

Esta publicação está disponível gratuitamente em: https://doi.org/10.6028/NIST.IR.8178port

Maio de 2017

INCLUDES UPDATES AS OF 11-07-2017;

SEE ACKNOWLEDGEMENTS PAGE

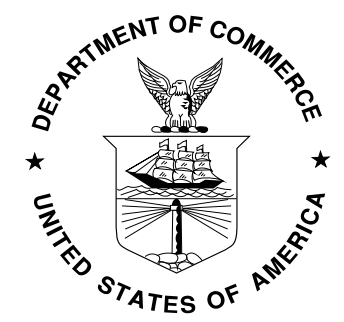

Departamento de Comérico Americano

Wilbur L. Ross, Jr., Secretário

Instituto Nacional de Padrões e Tecnologia Kent Rochford, Diretor Interino do NIST e Subsecretário de Comércio para Padrões e Tecnologia 


\section{Agradecimentos}

As autoras principais deste documento são Karen Reczek, NIST, e Lisa M. Benson, Dakota Consulting, contratada pelo Escritório de Coordenação de Padrões do NIST. A orientação adicional, a pesquisa inicial e a revisão do documento foram fornecidas pelo pessoal do Escritório de Coordenação de Padrões do NIST, incluindo: Mary Donaldson e Erik Puskar. Apoio valioso também foi recebido de especialistas renomados da Comissão de Segurança de Produtos ao Consumidor (CPSC), Agência de Proteção Ambiental (EPA), Administração de Alimentos e Fármacos (FDA), Comissão de Comércio Federal (FTC), Associação dos Fabricantes e Distribuidores de Cosméticos (ICMAD). Administração de Comércio Internacional (ITA), Conselho de Produtos de Cuidados Pessoais (PCPC) e UL, Inc. que forneceu informações para o documento e realizou uma revisão completa. Da CPSC: Mary Boyle, Patricia Pollitzer e Mary Toro; da EPA: Keith Mason e Alexander Metcalf; da FDA: Jeffrey Read, Linda Katz e Tracy DuVernoy; da FTC: Stephen C. Eckland e Julia Ensor; da ICMAD: Craig Weiss; da ITA: Tracy Gerstle.

\section{Ressalva}

Algumas entidades comerciais são identificadas neste documento para especificar o procedimento experimental adequadamente. Tal identificação não pretende implicar em recomendação ou endosso por parte do Instituto Nacional de Padrões e Tecnologia nem pretende significar que os materiais ou equipamentos identificados sejam necessariamente os melhores disponíveis para o propósito.

\section{Disclaimer}

This document was translated courtesy of the National Institute of Standards and Technology (NIST).

This translation is not an official US Government or NIST translation. The US Government does not make any representations as to the accuracy of the translation.

The official English language version of this publication is available free of charge from the National Institute of Standards and Technology (NIST): https://doi.org/10.6028/NIST.IR.8178 


\section{ÍNDICE}

Como usar este guia 1

Escopo 1

Visão Geral da Estrutura Regulatória Federal Americana. 2

Autoridades Regulatórias Federais e Regulamentos Técnicos (Obrigatório) ..... .2

Comissão de Segurança de Produtos Destinados ao Consumidor (CPSC - Consumer Product Safety Commission).

Lei de Segurança de Produtos Destinados ao Consumidor (CPSA - Consumer Product

Safety Act). 3

Embalagem Resistente à Manipulação por Crianças.....................................................................

Sabonete .4

Lei de Melhoria da Segurança de Produtos Destinados ao Consumidor de 2008 (CPSIA -

Consumer Product Safetu Act). . .4

Cosméticos Infantis . .5

Lei Federal de Substâncias Perigosas (FHSA). .5

Alfândega e Proteção de Fronteiras (CBP - Customs and Border Protection)... 6

País de Origem: Marcação de Artigos Importados e Recipientes ..... 6

Agência de Proteção Ambiental (EPA - Environmental Protection Agency).

Lei Federal de Inseticidas, Fungicidas e Raticidas (FIFRA - Federal Insecticide,

Fungicide and Rodenticide Act).

Produtos não Essenciais Contendo Clorofluorocarbonos (CFCs) e

Hidroclorofluorocarbonos (HCFCs)....

Compostos Orgânicos Voláteis (COVs) e Compostos Orgânicos de Alta Volatilidade (COAVs) .7

Comissão Federal de Comércio (FTC - Federal Trade Commission).........................................8

A Lei FTC

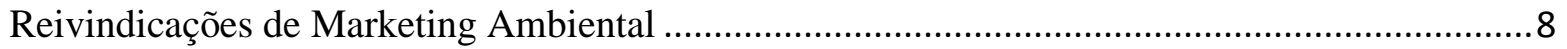

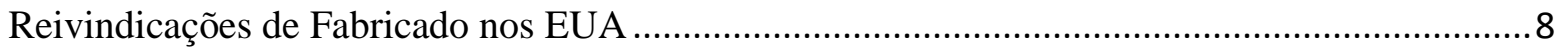

Administração de Alimentos e Fámacos (FDA) .....................................................................9

Lei de Alimentos, Fármacos e Cosméticos (FD\&C Act) …...................................................... 9

Rotulagem de Cosmético................................................................................................ 10

Ingredientes de Cosméticos ........................................................................................... 11

Declarações de advertência e cuidado para cosméticos ..........................................................11

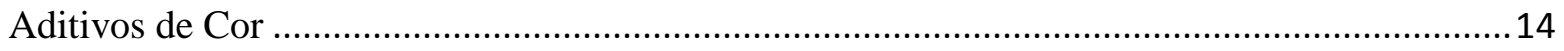

Documentos de Orientação Pendentes Dignos de Nota: ......................................................15 


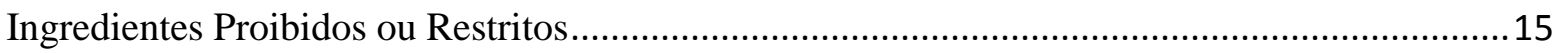

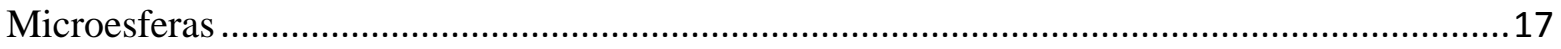

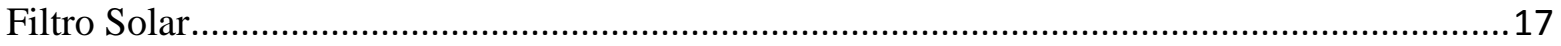

Embalagem Resistente à Violação ..................................................................................... 19

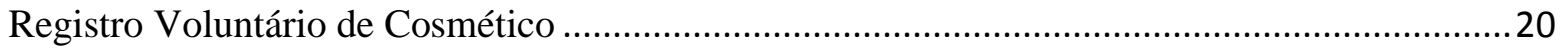

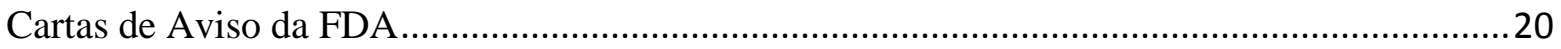

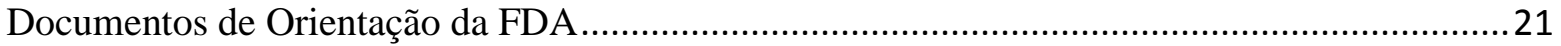

Departamento Americano de Agricultura (USDA - United States Department of

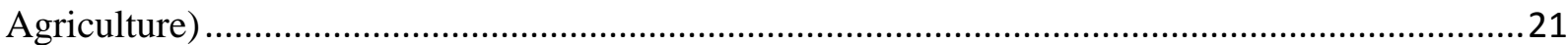

Reivindicações Orgânicas - Lei de Produção de Alimentos Orgânicos de 1999 (OFPA -

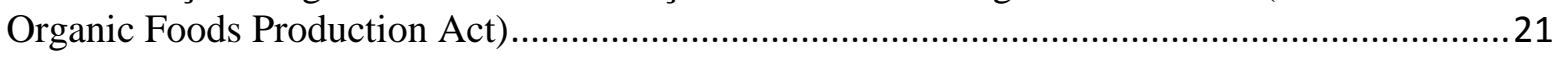

Visão Geral das Estruturas Regulatórias Estaduais Americanas .....................................................22

1. Autoridades Regulatórias Estaduais e Regulamentos Técnicos (Obrigatório)........................22

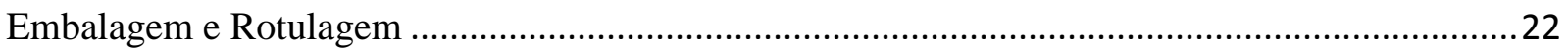

Leis e Regulamentações Uniformes (UPLR - Uniform Laws and Regulations).........................22

Tóxicos na Legislação de Embalagem ...............................................................................23

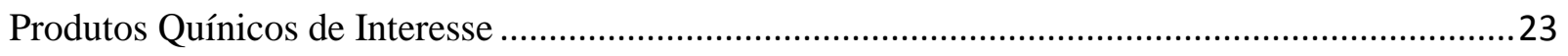

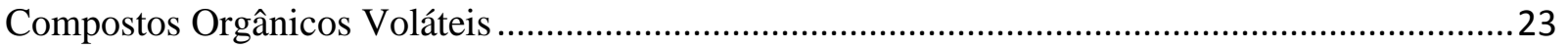

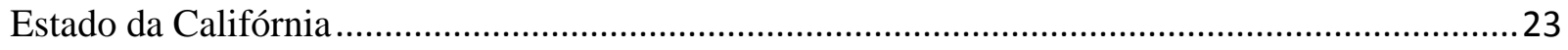

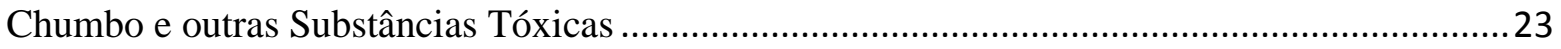

Lei de Cosméticos Seguros da Califórnia ..........................................................................25

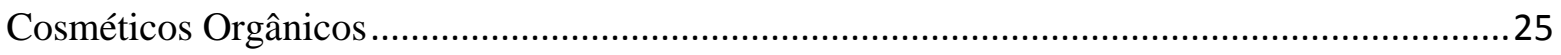

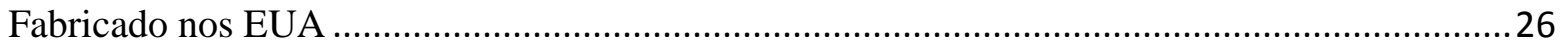

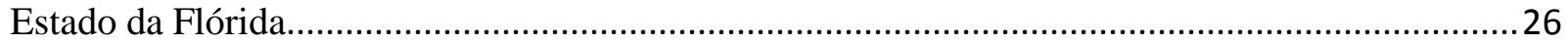

Permissão do Fabricante de Produto Cosmético ........................................................................26

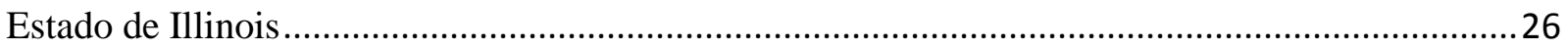

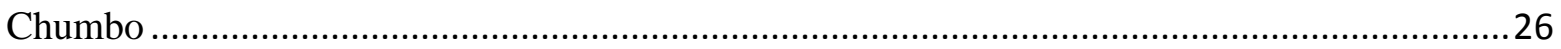

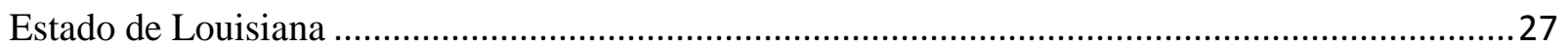

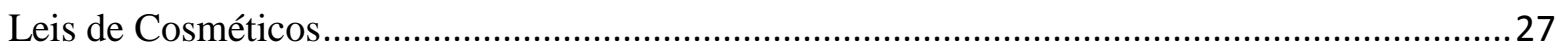

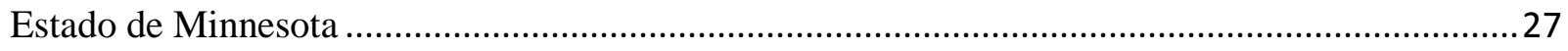

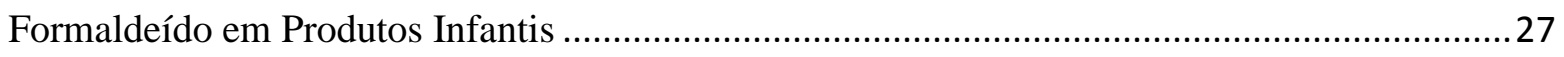

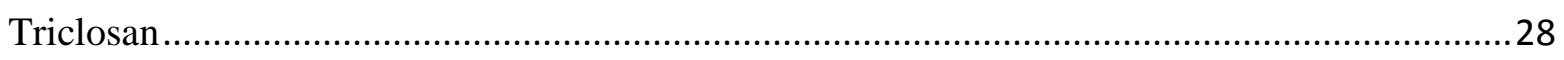

Visão Geral da Estrutura de Padrões Voluntários dos EUA ............................................................28

Organizações de Desenvolvimento de Padrões (SDOs) ...............................................................28 


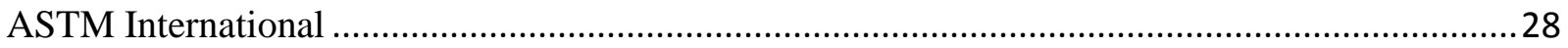

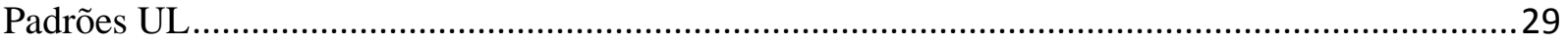

Convenção da Farmacopeia dos EUA (USP - U.S. Pharmacopeia).................................................2 29

Organização de Padrões Internacionais (ISO - International Standards Organization) .....................30

Entidades de Teste e Certificação .........................................................................................................

Laboratórios de Teste ………………………………………………………………………....

Procedimentos de Teste ....................................................................................................

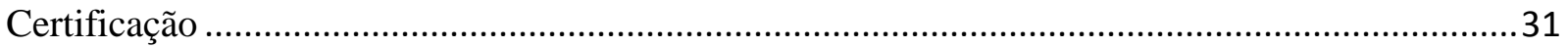

Produtos Sujeitos às Regras de Segurança de Produto Destinado ao Consumidor .......................31

Agências Governamentais Americanas Relevantes ............................................................................. 33

Comissão de Segurança de Produtos Destinados ao Consumidor (CPSC) .........................................33

Alfândega e Proteção de Fronteiras Americana (CBP) ...............................................................

Agência de Proteção Ambiental (EPA - Environmental Protection Agency) ......................................33

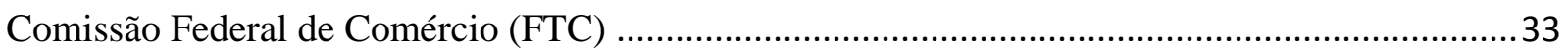

Administração de Alimentos e Fármacos (FDA) ……………………………………………......

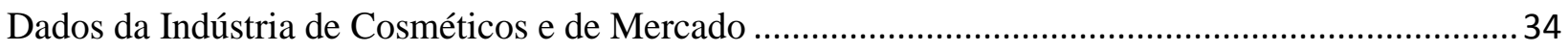

Associações Comerciais da Indústria .......................................................................................

Revisão de Ingrediente Cosmético (CIR - Cosmetic Ingredient Review)....................................34

Nomenclatura Internacional para Ingredientes Cosméticos (INCI - International

Nomenclature for Cosmetics Ingredients) .............................................................................

Fabricantes e Distribuidores de Cosméticos Independentes (ICMAD - Independent

Cosmetic Manufacturers and Distributors) ……………........................................................

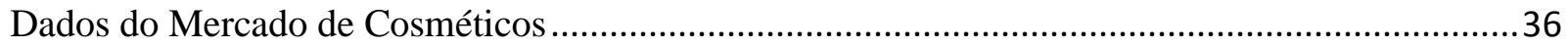




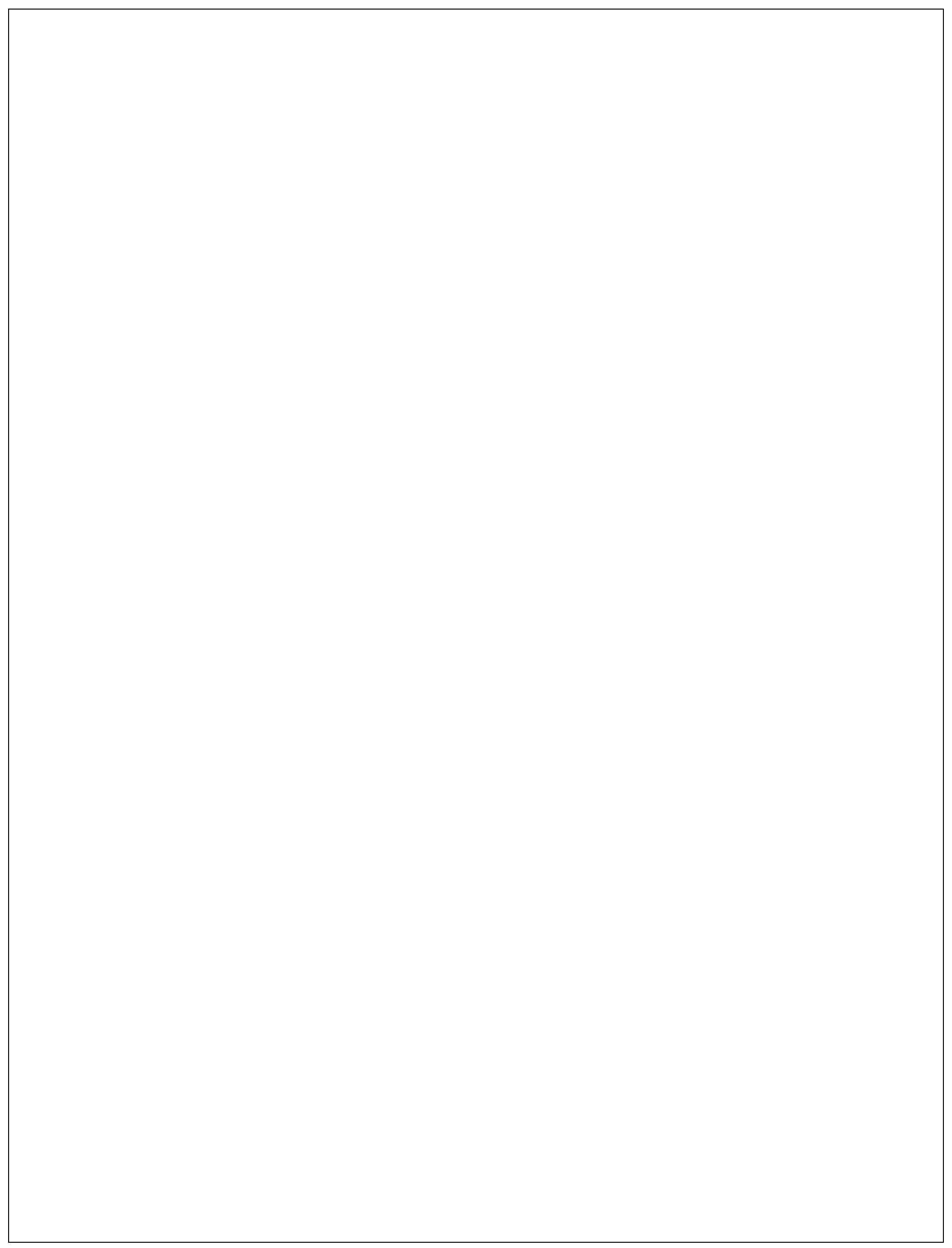




\section{Guia para os Requisitos de \\ Conformidade de Cosméticos \\ dos Estados Unidos}

\section{COMO USAR ESTE GUIA}

- As regulamentações são obrigatórias

- Os padrões são voluntários (a menos que "Incorporados como referência" na regulamentação)

- As diretrizes podem ser voluntárias (mas são, frequentemente, de fato, os padrões da indústria)

- O texto em "Vermelho "destaca os requisitos obrigatórios

- O texto em "Azul "indica um hiperlink para um site, página ou documento na web

\section{ESCOPO}

Este guia trata dos requisitos de conformidade para cosméticos basicos e sabonetes. A Lei Federal de Alimentos, Fármacos e Cosméticos (FD\&C Act - Federal Food, Drug and Cosmetic Act) define cosméticos como "artigos destinados a serem esfregados, derramados, polvilhados ou pulverizados, introduzidos ou de outra forma aplicados ao corpo humano... para limpeza, embelezamento, promoção de atrativo ou alteração de aparência" (FD\&C Act, seção 201(i)). Os produtos cosméticos podem incluir hidratantes para a pele, perfumes, batons, esmaltes para unhas, preparações para maquiagem do olho e facial, xampus de limpeza, produtos para permanente, tintas para o cabelo e desodorantes, bem como qualquer substância cujo uso pretendido seja como um componente de um produto cosmético.

Este documento de orientação não cobre fármacos ou produtos farmacêuticos de venda livre (OTC - over-the counter) (como xampus anticaspa) ou produtos que têm propriedades cosméticas e medicamentosas, exceto filtros solares, que são tratados neste guia. A FDA define fármaco como qualquer substância cujo uso pretendido seja em diagnóstico, cura, mitigação, tratamento ou prevenção de doenças ou que afete a estrutura ou função do corpo.

Este guia também não trata dos requisitos de conformidade de brimquedos que possam ser incluídos em cosméticos infantis.

Para mais informações, consulte a FDA em:

É cosmético, fármaco ou ambos? (Ou é sabonete?) 


\section{VIsÃo Geral da Estrutura RegUlatória Federal Americana}

Assim que uma lei é promulgada pelo Congresso, a agência federal apropriada (por exemplo, a Comissão de Segurança de Produto Destinado ao Consumidor, a Comissão Federal de Comércio, a Administração Nacional de Tráfego e Segurança em Rodovias, etc.) pode criar a regulamentação para implementar a lei. Antes que tais regulamentações possam ser adotadas, a agência federal apropriada normalmente emitirá um aviso de consulta pública da regulamentação proposta (NPRM - notice of proposed rulemaking) para solicitar comentários públicos sobre as regras propostas. Para dar a oportunidade de comentários públicos, a agência federal apropriada precisa emitir um rascunho das regulamentações ou "Regras Propostas" que são publicadas no Federal Register (e que, subsequentemente, são notificadas como notificações do Acordo com a Organização Internacional de Comércio sobre Barreiras Técnicas para Comércio (WTO TBT) pela Autoridade Americana de Notificação da WTO TBT no NIST). A agência revisa cuidadosamente todos os comentários e modifica a regra proposta, como apropriado, com base no registro. A agência pode, então, emitir uma Regra Final que também é publicada no Federal Register e, posteriormente, publicada anualmente no Código Federal de Regulamentações (CFR - Code of Federal Regulations). Em conjunto, os decretos e leis de habilitação (publicados no Código dos Estados Unidos (USC - United States Code) assim que promulgados) e as regulamentações finais (publicadas no CFR) fornecem uma estrutura para a implementação e promulgação da maioria das leis federais nos Estados Unidos.

\section{AUtORIDADES REgULATÓRIAS FEDERAIS E REgULAMENTOS TÉCNICOS (OBRIGATóRIO)}

\begin{tabular}{|l|l|}
\hline Agência & Escopo \\
\hline $\begin{array}{l}\text { Comissão de Segurança de Produtos Destinados ao } \\
\text { Consumidor (CPSC - Consumer Product Safety } \\
\text { Commission) }\end{array}$ & $\begin{array}{l}\text { Segurança de produtos, produtos infantis, sistemas de } \\
\text { fechamento resistentes à manipulação por crianças, } \\
\text { sabonetes }\end{array}$ \\
\hline $\begin{array}{l}\text { Alfândega e Proteção de Fronteiras (CBP - Customs } \\
\text { and Border Protection) }\end{array}$ & $\begin{array}{l}\text { País de origem (para a maioria dos produtos } \\
\text { importados, licenciamento e composição) }\end{array}$ \\
\hline $\begin{array}{l}\text { Agência de Proteção Ambiental (EPA - } \\
\text { Environmental Protection Agency) }\end{array}$ & $\begin{array}{l}\text { Lei Federal de Inseticidas, Fungicidas e Raticidas; } \\
\text { substâncias depletoras de ozônio }\end{array}$ \\
\hline $\begin{array}{l}\text { Comissão Federal de Comércio (FTC - Federal } \\
\text { Trade Commission) }\end{array}$ & $\begin{array}{l}\text { Práticas comerciais injustas. reclamações ambientais e } \\
\text { de desempenho de produto }\end{array}$ \\
\hline $\begin{array}{l}\text { Administração de Alimentos e Medicamentos (FDA } \\
\text { - Food and DrUg Administration) }\end{array}$ & $\begin{array}{l}\text { Regulamentações de cosméticos, microesferas, } \\
\text { aditivos de cor, regulamentações de ingredientes } \\
\text { cosméticos, embalagem e rotulagem de cosméticos } \\
\text { (incluindo os requisitos da CPSC para cosméticos) }\end{array}$ \\
\hline $\begin{array}{l}\text { Departamento Americano de Agricultura (USDA - } \\
\text { United States Department of Agriculture) }\end{array}$ & Reivindicações orgânicas \\
\hline
\end{tabular}




\title{
Comissão de Segurança de Produtos Destinados ao Consumidor (CPSC - Consumer Product Safety Commission)
}

\author{
Lei de Segurança de Produtos Destinados ao Consumidor (CPSA - Consumer Product Safety Act) \\ Título 15, Código dos Estados Unidos, Capítulo 47, Seções 2059-2089
}

A Lei de Segurança de Produto Destinado ao Consumidor (CPSA), tornou-se lei em 27 de outubro de 1972, foi promulgada para estabelecer a Comissão de Segurança de Produtos Destinados ao Consumidor (CPSC) e define sua autoridade com o propósito de proteger o público contra riscos não razoáveis de ferimentos associados aos produtos destinados ao consumidor; auxiliar os consumidores na avaliação de segurança comparativa de produtos destinados ao consumidor; desenvolver padrões de segurança uniformes para os produtos destinados ao consumidor; e promover pesquisa e investigação das causas e prevenção de mortes, doenças e ferimentos relacionados ao produto.

\section{Embalagem Resistente à Manipulação por Crianças}

A Lei de Embalagem para Prevenção de Envenenamento dá à CPSC a autoridade para regular as embalagens resistentes à manipulação por crianças (ERMC). A Lei, juntamente com as Regulamentações, 16 CFR 1700 , são preparadas para reduzir o risco de crianças menores de cinco anos ingerirem substâncias domésticas potencialmente perigosas ao requerer embalagens ERMC para substâncias específicas. Embalagem ERMC ou especial, como é chamada nas Regulamentações, é a embalagem que é projetada ou construída para ser significativamente difícil (dentro de um período de tempo razoável) para crianças menores de cinco anos de idade abrirem ou acessarem uma quantidade tóxica ou perigosa da substância. A embalagem ERMC não pode ser difícil para a maioria dos adultos usarem de forma apropriada.

De acordo com as Regulamentações, a embalagem ERMC é requerida para certas substâncias, incluindo, mas não se limitando a:

- Salicilato de metila - preparações líquidas contendo mais de 5 por cento, em peso

- Metanol - forma líquida contendo 4 por cento ou mais, em peso

- Etileno glicol - formas líquidas contendo 10 por cento ou mais, em peso

- Removedores de cola contendo acetonitrila - formas líquidas contendo mais de 500 miligramas de acetonitrila em um recipiente único

- Ácido metacrílico - forma líquida contendo mais de 5 por cento (peso para volume) em um pacote de varejo único

- Produtos líquidos não emulsão que contêm 10 por cento ou mais de hidrocarbonetos, em peso, e têm uma viscosidade menor que 100 SUS a $38^{\circ} \mathrm{C}\left(100^{\circ} \mathrm{F}\right)$

Consulte as Regulamentações para substâncias adicionais e exceções.

Embalagens ERMC precisam satisfazer as especificações de desempenho apresentadas em $\underline{16 \text { CFR }}$ $\underline{1700.15}$ de acordo com o teste, conforme detalhado em $\underline{16 \text { CFR 1700.20. }}$

A Regulamentação permite que o fabricante ou embalador embale um produto de venda livre sujeito a padrões de embalagem especiais em um tamanho de embalagem não ERMC, apenas se o fabricante (ou embalador) também fornecer a substância em embalagens ERMC em um tamanho popular e as embalagens não ERMC apresentem uma rotulagem proeminente declarando: "Esta embalagem é para famílias sem crianças pequenas." 
O fabricante ou importador americano deve fornecer um Certificado Geral de Conformidade para a embalagem ERMC que se baseie em teste de cada produto ou um programa de teste razoável.

\author{
Para informações adicionais, consulte a página na web da CPSC: \\ Lei de Embalagem para Prevenção de Envenenamento \\ Orientação de Negócios da Lei de Prevenção de Envenenamento \\ Lei de Segurança de Produtos Destinados ao Consumidor \\ Certificado Geral de Conformidade
}

\title{
Sabonete
}

A Lei FD\&C especificamente exclui sabonete da definição de cosmético e é, portanto, regulado quanto à segurança, pela CPSC sob a Lei Federal de Substância Perigosa (FHSA - Federal Hazardous Substance Act), 15 U.S.C. 1261. De acordo com 21 CFR 701.20, a FDA interpreta o termo sabonete como aplicando-se apenas a artigos que satisfazem o seguinte:

- O material a granel do material não volátil no produto consiste em um sal álcali de ácidos graxos e as propriedades detergentes do artigo devem-se aos compostos álcali-ácido graxo; e

- o produto é rotulado, vendido e representado apenas como sabonete.

Os produtos concebidos para limpeza do corpo humano que não são considerados sabonete (conforme definido acima) são considerados cosméticos (por exemplo, concebidos para hidratar ou desodorizar o corpo) ou fármacos (por exemplo, concebidos para tratar condições da pele ou reivindicações antimicrobianas) e estão sujeitos aos requisitos apropriados da Lei FD\&C e regulamentações da FDA. Se nenhuma reivindicação for feita, além de sabonete, a rotulagem do ingrediente é apenas requerida para qualquer ingrediente que estaria relacionado a um dos perigos tratados sob a FHSA. Entretanto, o sabonete está sujeito aos requisitos da Lei de Embalagem e Rotulagem Justas (FPLA - Fair Packaging and Labeling Act), conforme administrado pela FTC.

\section{Lei de Melhoria da Segurança de Produtos Destinados ao Consumidor de 2008 (CPSIA - Consumer Product Safetu Act)}

Lei de Ordem Pública 110-314, 14 de agosto de 2008

Em 14 de agosto de 2008, o Presidente assinou a Lei de Ordem Pública 110-314 (Lei de Melhoria de Segurança de Produto Destinado ao Consumidor de 2008). Em 12 de agosto de 2011, ele assinou as emendas da lei, Lei de Ordem Pública 112-28, 12 de agosto de 2011. A Lei forneceu à CPSC novas ferramentas significativas regulatórias e de execução como parte das emendas e aprimorou vários estatutos da CPSC, incluindo a Lei de Segurança de Produto Destinado ao Consumidor.

A Lei de Melhoria da Segurança do Produto Destinado ao Consumidor (CPSIA) fornece requisitos adicionais para os produtos infantis, incluindo limites de substâncias específicas. A CPSIA limita o teor de chumbo e ftalatos em brinquedos, artigos de puericultura e substâncias. Um produto infantil é definido como um produto destinado ao consumidor projetado ou concebido principalmente para crianças até 12 anos. 


\section{Cosméticos Infantis}

A regulamentação de cosméticos fica, em geral, fora da jurisdição da CPSC. Entretanto, com relação aos brinquedos infantis que incluem cosméticos, Seção 101(a) de CPSIA restrige o brinquedo e quaisquer produtos infantis, conforme descrito no estatuto, a um limite de teor de chumbo de 100 partes por milhão (ppm). Além disso, o uso de tinta ou revestimento de superfície similar nos produtos infantis não podem exceder um limite de teor de chumbo de 90 ppm. A embalagem dos cosméticos infantis está sujeita a limites no teor de chumbo e de chumbo na titna e coberturas de superfície similares.

Adicionalmente, a Seção 108 da CPSIA declara que certos brinquedos infantis e artigos de puericultura não podem conter mais de $0,1 \%$ de seis ftalatos - os limites de ftalato de di-(2-etilhexila) (DEHP), ftalato de dibutila (DBP) e ftalato de benzil butila (BBP) são aplicáveis a brinquedos e itens de puericultura, enquanto que os limites de ftalato de di-isononila (DINP), ftalato de diisodecila(DIDP) e ftalato de di-n-octila (DnOP) são aplicáveis apenas a artigos de puericultura e brinquedos que sejam concebidos para crianças até três anos de idade e que possam ser colocados na boca.

Apesar de os cosméticos infantis não embalados com um brinquedo para crianças estarem sujeitos aos requisitos apropriados da Lei FD\&C e das regulamentações da FDA, a embalagem e os recipientes contendo os cosméticos infantis estão sujeitos à conformidade com a CPSIA sendo ou não embalados com brinquedos. Os brinquedos estão sujeitos a testes e certificação, que não estão dentro do escopo deste guia.

\section{Lei Federal de Substâncias Perigosas (FHSA)}

Título 15, Código dos Estados Unidos, Capítulo 30, Seções 1261-1278

16 CFR 1500, Regulamentações da Lei Federal de Substâncias Perigosas (FHSA)

A Lei Federal de Substâncias Perigosas (FHSA) e as regulamentações emitidas de acordo com ela, estabelecem requisitos para substâncias perigosas que são concebidas ou embaladas em uma forma adequada para uso das famílias. A definição da FHSA de "substâncias perigosas" exclui produtos que são considerados cosméticos sob a Lei FD\&C. Entretanto, os produtos que satisfazem a definição da FDA de "sabonete" não são cosméticos e, dessa forma, estão sujeitos à FHSA. Os cosméticos podem ser considerados mal rotulados de acordo com a Lei FD\&C, a menos que o rótulo do produto siga a orientação da FDA a respeito de ingredientes, avisos e a classificação de um produto com base em sua função de embelezar.

A FHSA requer que substâncias domésticas que satisfaçam a definição de perigosas (conforme definido na lei) apresentem rotulagem de advertência para avisar o consumidor sobre o(s) perigo(s) associado(s) ao uso do produto, instruções para uso e armazenamento seguros, instruções de primeiros socorros, quando aplicável, e a declaração "manter longe do alcance das crianças". Se o rótulo de um produto precisa conter rotulagem de advertência ou não depende de sua formulação e a probabilidade de que os consumidores serão expostos a quaisquer perigos que o produto apresente no uso comum, o que inclui ingestão pelas crianças. A FHSA define como substância perigosa banida aqueles produtos que são concebidos para uso por crianças e apresentem um perigo elétrico, mecânico ou térmico, com algumas exceções. A Lei também permite à CPSC banir certos produtos que são tão perigosos ou que a natureza do perigo é tal que a rotulagem requerida pela Lei não é adequada para proteger os consumidores. 


\title{
Alfândega e Proteção de Fronteiras (CBP - Customs and Border Protection)
}

\begin{abstract}
País de Origem: Marcação de Artigos Importados e Recipientes
Título 19, Código dos Estados Unidos, Capítulo 4, Seções 1304

Todos os produtos importados para os Estados Unidos precisam adaptar-se às Regulamentações $\underline{19}$ CFR 134, Marcação do País de Origem. Essas Regulamentações requerem que cada artigo de origem estrangeira (ou seu recipiente) que seja importado para os Estados Unidos seja marcado em um local proeminente de forma legível, indelével e permanente, conforme a natureza do artigo (ou recipiente) permitir, e de tal maneira a indicar ao comprador final nos Estados Unidos o nome em inglês do país de origem do artigo quando da importação.
\end{abstract}

\author{
Para informações mais detalhadas, consulte o item da CBP: \\ Importando cosméticos, sabonete, loção, xampu, instrumentos médicos e dentais para \\ revenda/propósitos comerciais
}

\section{Agência de Proteção Ambiental (EPA - Environmental Protection Agency)}

Muitas leis e regulamentações governam os requisitos de importação e exportação de materiais que podem representar risco à saúde humana e ao meio ambiente. A Agência de Proteção Ambiental (EPA) trabalha junto com os estados, outras agências federais e governos estrangeiros para assegurar a conformidade com as leis que governam a importação e exportação de muitos desses materiais.

\section{Lei Federal de Inseticidas, Fungicidas e Raticidas (FIFRA - Federal Insecticide, Fungicide and Rodenticide Act)}

A Lei Federal de Inseticidas, Fungicidas e Raticidas (FIFRA) fornece regulamentação federal para distribuição, venda e uso de pesticidas para proteger a saúde humana e o meio ambiente. Os produtos que matam ou repelem bactérias, germes ou insetos são considerados pesticidas e precisam ser registrados e avaliados quanto à segurança pela EPA antes de sua distribuição ou venda. A EPA não registrará um pesticida até que seja testado para mostrar que não representará um perigo não razoável quando usado de acordo com as instruções do produto. Isto inclui pesticidas em cosméticos que fornecem características antimicrobianas ou outras características pesticidas.

A FIFRA não permite que as empresas façam reivindicações de pesticidas de saúde pública para qualquer produto distribuído ou vendido a menos que o produto tenha sido aprovado e registrado pela EPA ou estiver coberto por uma exceção de registro. A EPA agirá contra empresas que façam tais reivindicações ilegais.

Produtos usando óleos essenciais como citronela ou hortelã pimenta também estão cobertos pela Regulamentação, mas podem ser considerados de risco mínimo e serem isentos de registro da FIFRA.

Para informações mais detalhadas, consulte o item da EPA:

Resumo da Lei Federal de Inseticidas, Fungicidas e Raticidas (FIFRA),

Registro de Pesticida avisos por Ano,

Regulamentação de Pesticidas, 
Rótulos de Produtos Pesticidas,

Regulamentação de Repelentes Aplicados à Pele, e

Pesticidas de Risco Mínimo Isentos de Registro na FIFRA

\section{Produtos não Essenciais Contendo Clorofluorocarbonos (CFCs) e Hidroclorofluorocarbonos (HCFCs)} Nos Estados Unidos, substâncias depletoras de ozônio são regulamentadas como substâncias controladas Classe I ou Classe II.

- As substâncias Classe I têm um potencial depletor de ozônio e foram completamente eliminados nos EUA, exceto para exceções permitidas pelo Protocolo de Montreal.

- As substâncias Classe II, hidroclorofluorocarbonos (HCFCs), que foram substitutos de transição para muitas substâncias Classe I, estão atualmente eliminadas.

Como um dos membros do Protocolo de Montreal, os EUA precisam eliminar o uso de HCFCs completamente até 2030. A Seção 605 do Lei do Ar Limpo estabelece uma programação para a eliminação da produção e consumo de HCFC, e restringe o uso de HCFC.

40 CFR 82 Subpart E estabelece requisitos de rotulagem específicos, incluindo uma declaração de advertência para produtos que contêm substâncias Classe I ou Classe II. Cada produto contendo uma substância Classe I ou Classe II precisa conter a seguinte declaração de advertência, satisfazendo os requisitos de colocação e forma:

AVISO: Contém [ou Fabricado com, se aplicável] [inserir o nome da substância], uma substância que prejudica a saúde pública e ambiental ao destruir o ozônio na camada superior da atmosfera.

Para informações mais detalhadas, consulte os itens da EPA:

Eliminação de HCFCs (Substâncias Depletoras de Ozônio Classe II) Ingredientes Proibidos e Restritos

\section{Compostos Orgânicos Voláteis (COVs) e Compostos Orgânicos de Alta Volatilidade (COAVs)}

40 CFR 59 Subpart C, Padrões Nacionais de Emissão de Composto Orgânico Volátil, estabelece limites para COVs e COAVs em produtos destinados ao consumidor incluindo fixadores para cabelos, mousses para cabelos, géis para pentear os cabelos, removedores de esmalte, cremes para barbear, antiperspirantes e desodorantes.

Além disso, o recipiente ou embalagem de cada produto destinado ao consumidor que esteja sujeito a esta subparte apresentará claramente o dia, mês e ano em que o produto foi fabricado ou um código indicando tal data. Os requisitos desta disposição não se aplicarão aos produtos que são oferecidos aos consumidores livres de encargos para os propósitos de amostra do produto. 


\title{
Comissão Federal de Comércio (FTC - Federal Trade Commission)
}

\author{
A Lei FTC \\ Título 15, Código dos Estados Unidos, Capítulo 2, Subcapítulo 1, Seções 41-58 \\ A Lei FTC amplamente proíbe atos ou práticas injustos ou enganosos no comércio ou afetando-o. A \\ Comissão achará que é enganoso se, por inclusão ou exclusão de informações, a representação, lei ou \\ prática: \\ - que seja provavelmente para enganar os consumidores atuando razoavelmente sob as \\ circunstâncias, e \\ que • seja importante e ferimento do consumidor seja provável.
}

A Comissão tem autoridade sob a Lei FTC para decretar regulamentações concebidas para proibir atos ou práticas injustos ou enganosos.

Para informações mais detalhadas, consulte o item da FTC:

Declaração de Política da FTC quanto à Fundamentação da Propaganda

Declaração de Política da FTC sobre Engano

\section{Reivindicações de Marketing Ambiental}

16 CFR 260, Guias para Uso de Reivindicações de Marketing Ambiental

Esses guias aplicam-se para reivindicações ambientais incluídas na rotulagem, propaganda, materiais promocionais e todas as outras formas de marketing, diretamente declaradas ou por dedução, através de palavras, símbolos, emblemas, logotipos, representações, nomes de marcas de produto ou através de quaisquer outros meios, incluindo propaganda através de meios digitais ou eletrônicos, como Internet ou correio eletrônico. Os guias aplicam-se a qualquer reivindicação a respeito dos atributos ambientais de um produto, embalagem ou serviço em conexão com a venda, oferta de venda ou comercialização de tal produto, embalagem ou serviço para uso pessoal, famíliar ou doméstico ou para uso comercial, institucional ou industrial.

Em 2012, a FTC atualizou as seções do guia sobre as reivindicações gerais de benefício ambiental, com teor compostável, degradável, ozônio, reciclável ou reciclado. Também adicionou novas seções sobre compensação de carbono, certificações e selos de aprovação, livres de reivindicações, reivindicações não tóxicas, feitos com reivindicações de energia renovável e com reivindicações de materiais renováveis.

\section{Para informações mais detalhadas, consulte o item da FTC:}

Reivindicações Ambientais: Resumo dos Guias Verdes

\section{Reivindicações de Fabricado nos EUA}

A Comissão Federal de Comércio monitora e executa as reivindicações de produto "Fabricado nos EUA", incluindo aquelas feitas para cosméticos. A Orientação da agência requer que os produtos que desejem fazer uma reivindicação não qualificada de "Fabricado nos EUA" precisam satisfazer "todo" ou "virtualmente todo" o padrão. 
Os estados também podem promulgar leis que governem quando uma reivindicação de "Fabricado nos EUA" puder ser feita para um produto. Por exemplo, de acordo com a lei revista da Califórnia "Fabricado nos EUA", "Fabricado na América", "EUA" ou rótulos similares são permitidos mesmo se o produto tiver alguns componentes estrangeiros. A rotulagem é permitida se qualquer componente ou peça estrangeiro não constituir mais de $5 \%$ do valor final de varejo do produto ou qualquer componente ou peça estrangeiro não constituir mais de $10 \%$ do valor final de varejo do produto $\mathrm{E} o$ fabricante puder demonstrar que esses componentes não podem ser obtidos ou produzidos domesticamente.

\section{Administração de Alimentos e Fámacos (FDA)}

Além da orientação fornecida aqui sobre os requisitos de conformidade americanos, a FDA oferece uma série de recursos para os importadores de produtos cosméticos para os EUA, com traduções disponíveis em espanhol, francês, chinês e coreano.

\section{Para mais informações, consulte o item da FDA}

Informações para Importadores de Cosméticos

\section{Lei de Alimentos, Fármacos e Cosméticos (FD\&C Act)}

A Lei Federal de Alimentos, Fármacos e Cosméticos (FD\&C Act) e os estatutos de emendas subsequentes são codificados no Título 21, Capítulo 9 do Código dos Estados Unidos. O propósito da Lei é assegurar que os alimentos, fármacos, dispositivos médicos e cosméticos sejam seguros e adequadamente rotulados. Capítulo VI da Lei (21 USC 361 a 363) contém a seção sobre cosméticos e trata de cosméticos adulterados e mal rotulados.

A introdução ou distribuição de cosméticos adulterados ou mal rotulados no comércio interestadual é uma ação proibida de acordo com a lei FD\&C. Um produto cosmético é considerado adulterado se ele ou seu recipiente contiver uma substância venenosa ou prejudicial que pode causar dano quando o produto é usado conforme indicado na rotulagem ou no uso costumeiro. Tintura para cabelos com alcatrão de tulha é uma exceção às disposições de adulteração da lei fornecidas desde que o produto seja rotulado com a seguinte declaração de advertência: "Cuidado - Este produto contém ingredientes que podem causar irritação da pele em certas pessoas e um teste preliminar de acordo com as indicações anexas deve ser feito primeiramente. Este produto não pode ser usado para tingir cílios nem sobrancelhas, pois pode causar cegueira."

Um produto cosmético também é considerado como estando adulterado se contiver qualquer substância suja, pútrida ou decomposta ou se for preparado, embalado ou mantido sob condições não sanitárias onde possa ficar contaminado com sujeira ou onde possa ser considerado danoso para a saúde. Adicionalmente, um cosmético, excluindo as tinturas para cabelos, não pode conter um aditivo de cor não seguro. Consulte Aditivos de Cor abaixo.

Um produto cosmético é considerado como estando mal rotulado se sua rotulagem for falsa ou enganosa e se o recipiente for feito, preenchido ou formado para ser enganoso. Isto inclui reivindicações de produtos que vão além da definição da FDA de cosmético. Além disso, a FDA emitiu 
regulamentações para rotulagem de cosméticos que podem ser encontradas em 21 CFR 701, que estabelecem os requisitos de rotulagem específicos para produtos cosméticos. As Regulamentações requerem, entre outras coisas, que os rótulos precisam conter o nome e local de negócios do fabricante, embalador ou distribuidor e uma declaração precisa de quantidade (peso, medição ou contagem numérica). Obs.: As unidades métricas são aceitáveis apenas como uma frase entre parênteses após unidades em polegada-libra.

Adicionalmente, as Regulamentações declaram que um rótulo pode ser considerado enganoso se o nome do produto sugerir ou incluir um ou mais nomes de ingredientes, mas não todos os ingredientes.

A FDA não requer liberação pré-comercialização das reivindicações do produto cosmético nem a agência tem uma lista específica de reivindicações cosméticas "aceitáveis" em comparação a "não aceitáveis". A FDA avalia as reivindicações do rótulo do cosmético no contexto total de todas as frases e imagens presentes nos rótulos e literatura promocional colateral (incluindo propaganda impressa e sites).

Os produtos também serão considerados como mal rotulados se qualquer palavra, declaração ou outra informação que é requerida por lei esteja faltando ou, de outro nodo, não esteja em conformidade com a colocação ou proeminência, conforme declarado nas Regulamentações. Toda a rotulagem requerida pelas Regulamentações precisam ser em inglês, exceto para produtos distribuídos unicamente em Porto Rico ou em um território onde o idioma predominante não seja o inglês. Entretanto, se o rótulo contiver qualquer representação em um idioma estrangeiro, então todas as informações requeridas também precisam estar no idioma estrangeiro.

Para informações mais detalhadas, consulte o item da FDA:

Autoridade da FDA sobre os Cosméticos

\section{Rotulagem de Cosmético}

A rotulagem dos cosméticos é regulada pela FDA sob autoridade da FD\&C Act e da Lei de Embalagem e Rotulagem Justas (FPLA). As informações a seguir precisam ser apresentadas no painel de exibição principal (o painel de exibição principal é definido para cosméticos em 21 CFR 701.10):

- Uma declaração de identidade indicando a natureza e uso do produto (consulte também $\underline{21}$ CFR 701.11)

- Uma declaração precisa da quantidade líquida dos conteúdos (consulte também 21 CFR $\underline{701.13})$

Além disso, o que se segue precisa aparecer no painel de informações:

- Nome e local de negócios - fabricante, embalador ou distribuidor (consulte também 21 CFR 701.12)

- Declaração do distribuidor se o nome não for do fabricante

- Fatos relevantes (por exemplo, para uso seguro)

- Declarações de aviso e cuidado

- Ingredientes listados em ordem descendente de predominância (consulte também 21 CFR $\underline{701.3}$ e $\underline{701.30}$ ) 
Obs.: A frase "Pode conter "pode ser usada para aditivos de cor em uma linha de produtos que tenha a mesma formulação com várias tonalidades diferentes, como batons ou sombras para os olhos (consulte 21 CFR 701.3(g)(1)). Nem a FD\&C Act nem a FDA definem o uso do termo "natural" ou "orgânico" em cosméticos.

\section{Ingredientes de Cosméticos}

De acordo com a FPLA, os ingredientes precisam ser listados por seus "nomes comuns ou usuais". A Seção $701.3($ c) das Regulamentações da FDA prescreve a nomenclatura para identificar os ingredientes na declaração do rótulo. A Regulamentação lista várias fontes para identificar o nome apropriado para um ingrediente e as fontes precisam ser consultadas na ordem em que aparecem na Regulamentação. A primeira fonte a consultar é a Seção 701.30, que é a Regulamentação que contém os nomes específicos estabelecidos pela FDA. As demais fontes são identificadas na Seção 701.3(c)(2). Muitas dessas fontes podem refletir os nomes dados para esses compostos químicos pelo grupo líder da indústria a Nomenclatura Internacional para Ingredientes Cosméticos (INCl - International Nomenclature for Cosmetic Ingredients). A FDA não aceita o uso de termos de outros idiomas, como nomes em latim para a rotulagem de ingredientes botânicos ou o uso do termo "Aqua" para "Água". A FDA, entretanto, permite o uso desses termos entre parênteses após o nome comum ou usual em inglês. "Fragrância" ou "Sabor" pode ser declarada como tal.

\section{Para informações mais detalhadas, consulte o item da FDA:} Nomes dos Ingredientes

\section{Declarações de advertência e cuidado para cosméticos}

21 CFR 740 Subpart A requer que os cosméticos que são perigosos para os consumidores quando utilizados de forma errada precisam ser rotulados com avisos apropriados e instruções adequadas para uso senão serão considerados como mal rotulados.

21 CFR 740.10 requer que cada ingrediente usado em um produto cosmético e cada produto cosmético acabado sejam adequadamente substanciados quanto à segurança antes da comercialização. Qualquer ingrediente ou produto cosmético cuja segurança não seja substanciada adequadamente antes da comercialização é considerado mal rotulado a menos que contenha a seguinte declaração proeminente no painel de exibição principal:

\section{Aviso -A segurança deste produto não foi determinada.}

Isto não constitui uma exceção às disposições de adulteração da Lei ou a qualquer outro requisito da Lei.

21 CFR 740.11 requer que o rótulo de um cosmético embalado em um recipiente auto-pressurizado e concebido para ser expelido da embalagem mediante pressão conterá o seguinte aviso: 
Aviso - Evitar pulverizar nos olhos. Conteúdo sob pressão. Não perfurar ou incinerar. Não armazenar em temperatura acima de $49^{\circ} \mathrm{C}\left(120^{\circ} \mathrm{F}\right)$. Manter longe do alcance das crianças.

O aviso pode ser alterado quando qualquer uma das circunstâncias abaixo estiver presente.

- No caso de produtos concebidos para uso por crianças, a frase "exceto sob supervisão de um adulto" pode ser adicionada ao final da última sentença do aviso.

- No caso de produtos embalados em recipientes de vidro, a palavra "quebrar" pode substituir "perfurar" no aviso.

- No caso de um produto não expelido como uma aspersão, as palavras "Evitar pulverizar nos olhos" pode ser removida do aviso.

Além do aviso, o rótulo de um cosmético embalado em um recipiente auto-pressurizado em que o propelente consiste totalmente ou em parte em um halocarboneto ou um hidrocarboneto deve conter o seguinte aviso:

\section{Aviso - Usar somente como indicado. 0 uso indevido intencional concentrando e a inalação deliberada do conteúdo podem ser nocivos ou fatais.}

Os produtos a seguir são isentos de uso indevido intencional pelo aviso de inalação acima.

- Produtos expelidos na forma de uma espuma ou creme que contêm menos de 10 por cento de propelente no recipiente.

- Produtos em um recipiente com uma barreira física que evita o escape do propelente quando do uso.

- Produtos com uma quantidade líquida de conteúdo menor que $50 \mathrm{ml}$ ( 2 oz) que são projetados para liberar uma quantidade medida de produto a cada válvula de ativação.

- Produtos com uma quantidade líquida de conteúdo menor que $15 \mathrm{ml}$ (1/2oz).

Os cosméticos embalados em um recipiente auto-pressurizado contendo ou fabricado com um propelente de clorofluorocarboneto ou outra substância depletora de ozônio precisa satisfazer os requisitos preparados pela EPA estabelecidos em 40 CFR 82.

De acordo com 21 CFR 740.12, o rótulo de desodorante feminino em spray precisa ter o seguinte aviso: 
Cuidado - Apenas para uso externo. Utilizar a pelo menos $20 \mathrm{~cm}$ de distância da pele. Não aplicar na pele rachada, irritada ou com prurido. Odor ou descarga persistente e não usual pode indicar condições para as quais um médico deve ser consultado. Descontinuar o uso imediatamente se erupção cutânea, irritação ou desconforto ocorrerem.

No caso de desodorantes femininos em spray cujo conteúdo expelido não contém popelente de gás liquifeito, como um propelente de halocarboneto ou hidrocarboneto, a declaração "Utilizar a pelo menos $20 \mathrm{~cm}$ de distância da pele" não é requerido.

O desodorante feminino em spray será considerado mal rotulado se o rótulo contiver a palavra higiene, higiênico ou uma palavra similar ou qualquer palavra que represente ou sugira que o desodorante feminino em spray tem uma utilidade médica.

De acordo com 21 CFR 740.17, o rótulo de produtos para banho com detergente formador de espuma, exceto aqueles produtos que são rotulados como concebidos para uso exclusivamente por adultos, devem conter indicações adequadas para uso seguro e o seguinte aviso de cuidado:

Cuidado - Usar somente como indicado. O uso excessivo ou a exposição prolongada pode causar irritação da pele e do trato urinário. Descontinuar se erupção cutânea, vermelhidão ou coceira ocorrer. Consulte o médico se a irritação persistir. Manter longe do alcance das crianças.

No caso de produtos concebidos para uso por crianças, a frase "exceto sob supervisão de um adulto" pode ser adicionada a final da última sentença do aviso de cuidado.

Tintura com alcatrão de tulha contendo como ingrediente 4-metóxi- $m$-fenilenodiamina (2,4diaminoanisol) ou 4-metóxi- $m$-fenilenodiamina sulfato (2,4-diaminoanisol sulfato) precisam ter no painel de exibição principal do rótulo e em qualquer rotulagem que acompanha o produto o seguinte aviso:

Aviso - Contém um ingrediente que pode penetrar na pele e foi determinado como causador de câncer em animais de laboratório.

21 CFR 740.19 requer que preparações de bronzeadores que não contenham um ingrediente de filtro solar precisam apresentar o seguinte aviso na rotulagem: 
Aviso - Este produto não contém filtro solar e não protege contra queimadura de sol. A exposição repetida da pele não protegida durante o banho de sol pode aumentar o risco de envelhecimento da pele, câncer de pele e outros efeitos nocivos para a pele mesmo se você não se queimar.

As preparações para bronzeamento incluem géis, cremes, líquidos e outros produtos tópicos que são concebidos para fornecer efeitos cosméticos na pele ao mesmo tempo que bronzeiam através da exposição à radiação ultravioleta (UV) (por exemplo, hidratantes ou produtos condicionadores) ou para dar a aparência de um bronzeado ao conferir cor à pele através da aplicação de aditivos de cor aprovados (por exemplo, di-hidroxiacetona) sem a necessidade de exposição à radiação UV. As preparações para bronzeamento não oferecem proteção contra a radiação UV. Filtros solares e produtos oferecendo proteção contra o sol ou radiação UV são considerados medicamentos e estão sujeitos às regulamentações de fármacos da FDA.

\section{Aditivos de Cor}

As regulamentações a seguir referem-se aos aditivos de cor usados em alimentos, fármacos e cosméticos:

21 CFR 70 Regulamentações de Aditivo de Cor

21 CFR 73 Lista de Aditivos de Cor Isentos de Certificação

21 CFR 74 Lista de Aditivos de Cor Sujeitos a Certificação

21 CFR 80 Certificação de Aditivo de Cor

21 CFR 81 Especificações Gerais e Restrições Gerais para Aditivos de Cor Provisórios para Uso em Alimentos, Fármacos e Cosméticos

21 CFR 82 Lista de Cores e Especificações Certificados Provisoriamente

Aditivos de cor para uso em cosméticos precisam satisfazer a aprovação, as regulamentações para uso, as especificações e as restrições rígidas da FDA. Além disso, certos aditivos de cor derivados de petróleo estão sujeitos a certificação pela FDA para confirmar a composição e pureza de cada lote de aditivos de cor. Os aditivos de cor obtidos principalmente de plantas, fontes minerais ou animais são isentos de certificação; entrentanto, precisam cumprir com os requisitos de identidade, especificações, usos, restrições e rotulagem declarados nas Regulamentações.

Se uma cor em particular for isenta ou não de certificação, a cor não pode ser usada a menos que tenha sido aprovada especificamente para o uso pretendido. As restrições específicas incluem o uso de um aditivo de cor na área do olho, usando um aditivo de cor de uso externo nos lábios ou áreas cobertas por membrana mucosa e o uso de aditivos de cor em injeções, a menos que as Regulamentações permitam tais usos para aquele aditivo de cor específico.

Para informações mais detalhadas, consulte o item da FDA:

Aditivos de Cor e Cosméticos

Resumo dos Aditivos de Cor para Uso nos Estados Unidos em Alimentos, Fármacos, Cosméticos e Dispositivos Médicos 


\section{Documentos de Orientação Pendentes Dignos de Nota:}

Rascunho de Orientação para a Indústria: Chumbo em Produtos Cosméticos para os Lábios e Cosméticos Aplicados Externamente: Nível Máximo Recomendado (dezembro de 2016)

\section{Ingredientes Proibidos ou Restritos}

As regulamentações da FDA 21 CFR 700 Subpart B proibem ou restringem especificamente certos ingredientes que podem ser usados em produtos cosméticos, mas que podem ser nocivos para os usuários.

De acordo com 21 CFR 700.11, o bitionol tem sido usado em alguns produtos cosméticos como agente antibacteriano. Porém, quando usado topicamente, o bitionol pode causar fotossensibilidade persistente em algumas pessoas e há evidência que indica que pode produzir sensibilização cruzada com outros produtos químicos comumente usados como certas salicilanilidas halogenadas e hexaclorofeno, o Bitionol é uma substância nociva que pode tornar qualquer produto cosmético que o contenha nocivo para os usuários. Consequentemente, qualquer cosmético contendo bitionol é considerado como sendo adulterado de acordo com a seção 601(a) da Lei Federal de Alimentos, Fármacos e Cosméticos.

De acorco dom 21 CFR 700.13, preparações cosméticas contendo mercúrio foram representadas como agentes clareadores da pele. Qualquer produto cosmético contendo mercúrio será considerado adulterado a menos que:

- contenha menos de 1 parte por milhão (0,0001 por cento) calculado como metal de mercúrio e é inevitável sob condições de boas práticas de fabricação, ou

- é um cosmético concebido para uso apenas na área do olho, onde o mercúrio é usado como conservante e a um nível que não exceda 65 partes por milhão (0,0065 por cento), calculado como metal e não haja conservante substituto eficaz e seguro sem mercúrio disponível para uso no cosmético.

Cloreto de vinila é uma substância nociva que pode tornar qualquer produto em aerossol cosmético que o contenha em um ingrediente nocivo para os usuários. Consequentemente, de acordo com 21 CFR 700.14, qualquer produto em aerossol cosmético contendo cloreto de vinila como ingrediente é considerado como estando adulterado.

Salicilanilidas halogenadas (tribromsalan (TBS, 3,4',5-tribromossalicilanilida), dibromsalan (DBS, 4'5dibromossalicilanilida), metabromsalan (MBS, 3,5-dibromossalicilanilida) e 3,3',4,5'tetraclorossalicilanilida (TCSA)), que têm sido usados como agentes antimicrobianos em certos cosméticos, são fotossensibilizadores e sensibilizadores cruzados potentes, que podem causar distúrbios de pele incapacitantes e tornar qualquer cosmético que as contenha nocivos para os usuários. Portanto, de acordo com 21 CFR 700.15, qualquer produto cosmético que contenha tal salicilanilida halogenada como ingrediente em qualquer nível para qualquer propósito é considerado como estando adulterado.

De acordo com 21 CFR 700.16, complexos contendo zircônio são substâncias nocivas que podem tornar qualquer produto em aerossol cosmético que o contenha como ingrediente nocivo para os usuários. Consequentemente, qualquer produto em aerossol cosmético contendo complexos com zircônio como ingrediente é considerado como estando adulterado. 
De acordo com 21 CFR 700.18, clorofórmio é uma substância nociva que pode tornar qualquer produto cosmético que o contenha como ingrediente nocivo para os usuários. Qualquer produto cosmético contendo clorofórmio como ingrediente é considerado adulterado. O clorofórmio não é considerado como sendo ingrediente em nenhum produto cosmético onde é encontrado em quantidades residuais a partir de seu uso como um solvente de processamento durante a fabricação ou como subproduto da síntese de um ingrediente.

O uso de cloreto de metileno em produtos cosméticos representa um risco significativo de câncer para os consumidores e seu uso nos produtos cosméticos pode tornar esses produtos nocivos para a saúde. De acordo com 21 CFR 700.19, qualquer produto cosmético contendo cloreto de metileno como ingrediente é considerado como adulterado.

De acordo com 21 CFR 700.23, o uso de clorofluorocarbonos em cosméticos como propelente em recipientes auto-pressurizados é proibido.

De acordo com 21 CFR 700.27, nenhum cosmético será fabricado a partir de, processado com ou de outra forma conterá materiais provenientes de gado proibidos exceto pelas exceções da Regulamentação. Os materiais provenientes de gado proibidos são materiais de risco especificados, intestino delgado de todos os tipos de gado exceto se o íleo distal for removido por um procedimento que remova pelo menos $203 \mathrm{~cm}$ (80 polegadas) do intestino delgado desenrolado e aparado, material de gado com deficiência que não anda, material de gado que não inspecionado e foi aprovado ou foi mecanicamente separado (MS) (carne).

De acordo com 21 CFR 700.35, se um produto cosmético contiver um ingrediente de filtro solar para usos que não sejam proteção contra o sol e usa o termo "filtro solar" ou terminologia similar à proteção contra o sol em qualquer parte de sua rotulagem, o termo não pode ser qualificado pela descrição de benefício cosmético fornecido pelo ingrediente de filtro solar. A declaração precisa aparecer proeminente e conspicuamente pelo menos uma vez na rotulagem em conjunto com o termo "filtro solar" ou outra terminologia de proteção contra o sol usada na rotulagem. Por exemplo:

"Contém filtro solar - para proteger a cor do produto". Um produto que inclua o termo "filtro solar" em sua rotulagem que é concebido para evitar, curar, tratar ou mitigar doenças ou para afetar uma estrutura ou função do corpo é considerado um fármaco e precisa cumprir com as regulamentações de fármacos da FDA.

21 CFR 250.250 estabelece regulamentações para uso de hexaclorofeno antibacteriano em cosméticos. O hexaclorofeno pode ser usado como conservante em produtos cosméticos a um nível que não seja maior do que o necessário para obter a função conservante pretendida e não pode ser usado em níveis excedendo a 0,1 por cento. Não pode ser usado em cosméticos que são usados próximos a ou em membranas mucosas. O hexaclorofeno apenas pode ser usado em aplicações onde um conservante alternativo ainda não demonstrou ser tão eficaz ou onde dados de integridade e estabilidade adequados para o produto reformulado ainda não estão disponíveis.

Os ingredientes antibacterianos usados como substitutos para o hexaclorofeno em produtos cosméticos precisam ser adequadametne tratados quanto à segurança antes da comercialização. Sem testes de segurança antes da comercialização, o produto pode ser considerado adulterado e será 
considerado mal rotulado a menos que contenha uma declaração no painel frontal proeminente que o produto não foi adequadamente testado quanto à segurança e pode ser perigoso.

Para informações mais detalhadas, consulte o item da FDA:

Ingredientes Proibidos e Restritos

\section{Microesferas}

A Lei de Águas Isentas de Microesferas de 2015 emenda a Lei de Alimentos, Fármacos e Cosmético para banir a venda de cosméticos com enxágue, incluindo pasta de dentes, que contêm microesferas sintéticas intencionalmente adicionadas a partir de 1 de janeiro de 2018 e para banir a fabricação desses cosméticos a partir de 1 de julho de 2017. Uma microesfera plástica é definida como uma partícula plástica sólida que é menor que cinco milímetros em tamanho e é concebida para ser usada para esfoliar ou limpar o corpo humano. O banimento estatutório também se aplica a cosméticos que são fármacos que não necessitam de receita médica (de venda livre ou OTC), apesar de as datas de efetivação para cada uma das proibições aplicáveis a esses produtos ser escalonada por um ano a partir do início da aplicação aos produtos cosméticos.

\section{Filtro Solar}

Todos os produtos que reivindicam fornecer proteção de FPS de Amplo Espectro são regulados como fármacos com filtro solar. Isto aplica-se a cosméticos e hidratantes rotulados com valores de FPS, também.

Todos os filtros solares são regulados como fármacos nos Estados Unidos sob um dos seguintes processos:

- O novo processo de aprovação de fármacos descrito em 21 CFR 314

- O processo de monografia de fármaco de venda livre (também conhecido como Revisão de Fármaco de Venda Livre) descrito em 21 CFR 330, como complementado pela Lei de Inovação de Filtro Solar

A Lei de Inovação de Filtro Solar (SIA) fornece um processo para revisão de segurança e eficácia de ingredientes ativos de filtro solar que não necessitam de receita médica. A SIA estabelece uma linha de tempo muito específica para a FDA fazer uma determinação sobre um ingrediente ativo uma vez que todos os dados forem disponibilizados para a agência. A SIA emenda a Lei FD\&C em parte pelo fornecimento de novos procedimentos para estabelecer que os ingredientes de filtro solar, que não precisam de receita médica ou combinações de ingredientes ativos de filtro solar que não precisam de receita médica, são geralmente reconhecidos como seguros e eficazes (GRASE) e não mal rotulados quando usados sob as condições específicas em uma ordem de filtro solar final. Ingredientes ativos que são determinados como sendo GRASE em uma ordem de filtro solar final podem ser usados em filtros solares comercializados nos EUA sem primeiro obter um Pedido de Fármaco Novo (NDA, New Drug Application) ou Pedido de Fármaco Novo Abreviado (ANDA - Abbreviated New Drug Application).

\section{Rotulagem Baseada no Teste de Eficácia}

Os filtros solares precisam satisfazer os requisitos de rotulagem estabelecidos em 21 CFR 201.327. Isto aplica-se a produtos de filtros solares contendo ácido aminobenzoico, avobenzona, cinoxato, dioxibenzona, ensulizol, homosalato, meradimato, octinoxato, octisalato, octocrileno, oxibenzona, padimateo $\mathrm{O}$, sulisobenzona, dióxido de titânio, salicilato de trolamina ou óxido de zinco, sozinho ou em combinação. 
O que se segue precisa ser colocado no painel de exibição principal:

- Declaração de Identidade

- Reivindicação de Efetividade

- Para produtos que passam pelo teste de amplo espectro, a rotulagem precisa declarar "FPS de Amplo Espectro [inserir valor numérico de FPS resultante do teste]".

- Para produtos de filtro solar que não passam pelo teste de amplo espectro, a rotulagem precisa declarar "FPS [inserir valor numérico de FPS resultante do teste]".

- Declarações de Resistência à Água - para produtos que fornecem proteção contra água, de acordo com o teste, tanto por 40 como 80 minutos, a rotulagem deve declarar "Resistente à Água (40 minutos) ou (80 minutos)", conforme aplicável.

- Indicações - apenas os usos que foram estabelecidos podem ser incluídos. O seguinte precisa ser incluído sob o título Usos:

- [Marcador] Ajuda a evitar queimadura de sol

- [Marcador] Se usado conforme indicado com outras medidas de proteção contra o sol (consulte Indicações [em itálico e negrito]), diminui o risco de câncer de pele e envelhecimento precoce da pele causados pelo sol. [Isto somente é aplicável a filtros solares com um valor de FPS de Amplo Espectro de 15 ou maior de acordo com o teste. Qualquer rotulagem ou materiais promocionais que sugerem ou implicam que o uso, apenas, de qualquer filtro solar reduz o risco de ou evita o câncer de pele ou envelhecimento precoce da pele farão com que o produto seja mal rotulado]

- Avisos - Sob o título Avisos, o seguinte precisa aparecer:

- Em todos os produtos de filtro solar:

- Não usar [marcador] na pele danificada ou rachada.

- Ao usar este produto [marcador] mantenha longe dos olhos. Enxágue com água para remover.

- Interromper o uso e consultar um médico se [marcador] ocorrer erupção cutânea

- Nos produtos com filtro solar que são de amplo espectro com valores de FPS de pelo menos 2, mas inferiores a 15, de acordo com o teste de FPS:

- Alerta de câncer de pele/envelhecimento da pele [em negrito]; Ficar exposto ao sol aumenta o risco de câncer de pele e envelhecimento precoce da pele. Este produto demonstrou apenas ajudar a evitar queimadura de sol, não [em negrito] câncer de pele ou envelhecimento precoce da pele. [Esta precisa ser a primeira declaração sob o título Avisos.]

- Indicações

- Para todos os produtos de filtro solar:

- [marcador] aplicar [selecione um dos seguintes: Liberalmente ou generosamente] [e. como opção: E uniformemente] 15 minutos antes da exposição ao sol.

- [marcador] aplicar em toda a pele exposta ao sol [declaração opcional]

- [marcador] crianças menores de 6 meses de idade: consulte um médico

- Para produtos com filtros solares com um valor de FPS de Amplo Espectro de 15 ou maior de acordo com o teste:

- [marcador] Medidas de Proteção contra o Sol. [em negrito] Ficar exposto ao sol aumenta o risco de câncer de pele e envelhecimento precoce da pele. Para diminuir este risco, usar regularmente um filtro solar com um valor de FPS de 
Amplo Espectro de 15 ou maior e outras medidas de proteção contra o sol incluindo: [Marcador] limite o tempo ao sol, especialmente das 10 da manhã às 2 da tarde [marcador] usando blusas com mangas longas, calças, chapéus e óculos de sol

- Para produtos que satisfazem o teste de resistência à água:

- [marcador] reaplicar: [Marcador] após [selecione um dentre o seguinte determinado pelo teste de resistência à água: "40 minutos de" ou "80 minutos de"] natação ou suor [marcador] imediatamente após secar com a toalha [marcador] pelo menos a cada 2 horas.

- Para produtos que não satisfazem o teste de resistência à água:

- [marcador] reaplicar pelo menos a cada 2 horas [marcador] usar um filtro solar resistente à água se nadar ou suar

- Outras Informações

○ [marcador] proteger o produto em seu recipiente contra calor excessivo e sol direto

Reivindicações que são consideradas falsas e/ou enganosas nos produtos com filtro solar incluem, mas não se limitam a, o seguinte: "Protetor solar", "à prova de suor" e "à prova d'água". O uso dessas reivindicações ou similares farão o produto ser considerado mal rotulado.

Se o produto for uma combinação de filtro solar e protetor da pele. as declarações de identidade, indicações, avisos e indicação de uso, respectivamente, aplicáveis a cada ingrediente no produto podem ser combinados para eliminar palavras ou frases duplicadas de modo que as informações resultantes sejam claras e entendíveis.

\section{Embalagem Resistente à Violação}

Produtos de higiene oral cosméticos líquidos ou produtos usados vaginalmente que não têm embalagem resistente à violação ou não são rotulados adequadamente são considerados adulterados per 21 CFR 700.25 .

Uma embalagem resistente à violação é aquela que usa um indicador ou barreira de entrada que, quando quebrado ou esteja faltando, é visivelmente evidente para os consumidores que ocorreu violação. Para reduzir a probabilidade de substituição de um recurso de resistência à violação após a violação, o indicador ou a barreira de entrada é requerida de forma a ser característica devido ao design (por exemplo, um recipiente de produto de aerossol) ou pelo uso de uma característica de identificação (por exemplo, um padrão, nome, marca registrada, logotipo ou figura).

Exceto para os produtos em aerossol, cada embalagem de varejo de produtos de higiene oral cosméticos líquidos ou produtos usados vaginalmente deve apresentar uma declaração que seja proeminentemente colocada, de modo que os consumidores sejam alertados para o recurso resistente à violação específico da embalagem. A declaração da rotulagem precisa ser colocada de modo que não será afetada se o recurso resistente à violação da embalagem for quebrado ou estiver faltando. Se o recurso de resistência à violação usar uma característica de identificação para satisfazer o requisito, esta característica deve ser mencionada na declaração da rotulagem. Por exemplo, a declaração de rotulagem no frasco com uma faixa encolhível diria "Para sua proteção, este frasco tem uma vedação impressa ao redor do gargalo". 


\section{Registro Voluntário de Cosmético}

O Programa de Registro Voluntário de Cosmético da FDA (VCRP - Voluntary Cosmetic Registration Program), 21 CFR $\underline{710}$ e $\underline{720}$, é um sistema de relatório para uso por fabricantes, embaladores e distribuidores de produtos cosméticos que estejam em distribuição comercial nos Estados Unidos. A FDA usa as informações do VCRP para avaliar os produtos cosméticos no mercado. Dados de Frequência de Uso (FOU - Frequency of Use) do banco de dados do VCRP também são fornecidos pela FDA para o Programa de Painel Expecialista de Revisão de Ingredientes Cosméticos (CIR - Cosmetic Ingredient Review) fundado pela indústria e indenpendente. O CIR utiliza essas informações, juntamente com a literatura cientificamente válida disponível, para estabelecer as prioridades para aqueles ingredientes que o painel revisará, finalmente resultando na revisão do CIR e na avaliação da segurança do ingrediente. O VCRP também permite que os envasadores utilizem o banco de dados de segurança como armazenamento de segurança para informações sobre o produto. O programa somente é aplicável a produtos vendidos para consumidores não para produtos profissionais ou produtos que não são para venda, como amostras ou presentes de hotéis.

O banco de dados do VCRP não está disponível para o público; entretanto, a FDA fornecerá algunas informações, com base nas solicitações da Lei de Liberdade de Informação (FOIA - Freedom of information Act). Por exemplo, a FDA algumas vezes recebe tais solicitações de consumidores ou fornecedores de cuidados com a saúde que desejam identificar produtos que contenham ou não certos ingredientes. Informações comerciais proprietárias, entretanto, não serão liberadas mediante uma solicitação FOIA. As firmas podem enviar solicitações por escrito para confidencialidade de um ingrediente cosmético de acordo com 21 CFR 720.8, que também declara como a FDA lida com tais situações.

Há dois componentes do programa e o envolvimento do participante pode ser em um ou ambos os componentes;

21 CFR 710 delineia os requisitos para a porção de registro de estabelecimento voluntário do programa. Os proprietários ou operadores das instalações onde os cosméticos são fabricados e/ou embalados podem registrar seus estabelecimentos. A FDA designará um número de registro para cada local do estabelecimento.

21 CFR 720 delineia os requisitos para a parte de declarações de composição de ingrediente de produto cosmético qualitativo voluntárias do programa. No rótulo do produto, esses ingredientes serão listados na ordem descendente de predominância. Um fabricante, embalador ou distribuidor de cosmético pode protocolar uma declaração para cada produto que a firma distribui comercialmente nos Estados Unidos. A FDA designará um Número de Declaração de Ingrediente de Produto Cosmético (CPIS NO. - Cosmetic Product Ingredient Statement Number) para cada formulação protocolada no VCRP.

Para informações mais detalhadas, consulte o item da FDA:

Programa de Registro Voluntário de Cosmético

\section{Cartas de Aviso da FDA}

Quando a FDA determina que um produto cosmético está em violação da Lei FD\&C ou de uma regulamentação aplicável, a FDA tem autoridade para emitir uma carta de aviso para o fabricante ou distribuidor do produto. A carta de aviso tipicamente informará ao fabricante das violações alegadas e instruirá o fabricante que detalhe a ação corretiva que ele pretende tomar. Normalmente, a resposta 
precisa ser por escrito e enviada para o respectivo escritório distrital da agência, como delineado na carta de aviso recebida, dentro de 15 dias úteis. Não corrigir prontamente essas violações pode resultar em uma ação legal sem avisos adicionais, incluindo, sem limitação, apreensão dos produtos e/ou injunção contra as operações de fabricação continuadas.

Para mais informações, consulte o item da FDA:

Cartas de Aviso Relacionadas a Cosméticos

Sala de Leitura Eletrônica da FDA - Cartas de Aviso

\section{Documentos de Orientação da FDA}

A FDA preparou vários documentos de orientação que representam a interpretação da FDA de uma política sobre questões relacionadas a seu mandato regulatório. A orientação para a indústria no hiperlink acima inclui orientação específica para cosmético para boas práticas de fabricação, segurança de nanomaterial e mais. Os documentos de orientação não criam nem outorgam direitos para ou sobre qualquer pessoa e não operam para vincular a FDA ou o público. Uma abordagem alternativa pode ser usada se tal abordagem satisfizer os requisitos do estatuto, das regulamentações adequadas ou de ambos.

\section{Departamento Americano de Agricultura (USDA - United States Department of Agriculture)}

\section{Reivindicações Orgânicas - Lei de Produção de Alimentos Orgânicos de 1990 (OFPA - Organic Foods Production Act)}

Título 7, Código dos Estados Unidos, Capítulo 94, CERTIFICADO ORGÂNICO, Seções 6501-6523

O Departamento Americano de Agricultura (USDA - United States Department of Agriculture) regula o termo orgânico quando se aplica a produtos agrícolas através das Regulamentações do Programa Nacional Orgânico (NOP - National Organic Program), 7 CFR Part 205. As regulamentações do NOP incluem uma definição de orgânico e fornecem certificação de que os ingredientes agrícolas foram produzidos sob condições que satisfariam a definição. Também incluem padrões de rotulagem com base na porcentagem de ingredientes orgânicos em um produto, incluindo produtos cosméticos. Qualquer produto cosmético produzido em total conformidade com as regulamentações do NOP pode ser rotulado como orgânico certificado pelo NOP e apresentar o selo orgânico da USDA. Qualquer cosmético, produto para cuidados com o corpo ou produto para cuidados pessoais que não satisfaçam a produção, manuseio, processamento, rotulagem e padrões de certificação podem não declarar, dar a entender ou transmitir de qualquer forma que o produto é orgânico certificado pela USDA ou satisfaz os padrões orgânicos da USDA.

Entretanto, a USDA estipulou que não tem autoridade sobre a produção e rotulagem de cosméticos, produtos para cuidados com o corpo e produtos para cuidados pessoais que não sejam fabricados com ingredientes agrícolas ou que reivindicações não sejam feitas em relação à satisfação dos padrões orgânicos da USDA. A fiscalização regulatória para tal consmético e produtos para cuidados pessoais não tem precedência de jurisdição sobre a da FDA para o cumprimento geral dos requisitos regulatórios de segurança e rotulagem. "Orgânico" não é um termo regulado pela FDA, conforme observado neste documento. As reivindicações nesta área podem estar sujeitas à jurisdição da FTC.

Para informações mais detalhadas, consulte o item da USDA:

Programa Orgânico Nacional: Cosméticos, Produtos para Cuidados do Corpo e Produtos para Cuidados Pessoais 


\section{VISÃO GERAL DAS ESTRUTURAS REGULATÓRIAS ESTADUAIS AMERICANAS}

Um número crescente de áreas é coberto por estatutos estaduais e federais, incluindo proteção ao consumidor, emprego e regulamentação de alimentos e fármacos. As leis estaduais dão lugar a leis federais mais rígidas que tratam da mesma questão. Quando o governador do estado assina um projeto de lei, ele se torna uma lei estadual. Assim que a lei é promulgada por um estado, é responsabilidade da agência estadual apropriada criar as regulamentações necessárias para implementar a lei dentro do estado. Questões interestaduais são consideradas sob a jurisdição do Governo Federal Americano.

\section{Autoridades Regulatórias Estaduais e Regulamentos TÉcnicos (OBRIgatórIo)}

Nos EUA, algumas leis e regulamentações estaduais promulagadas são mais rígidas do que as leis federais. Essas leis incluem regulamentações para produtos, rotulagem, embalagem restrições químicas, etc.

\begin{tabular}{|l|l|}
\hline Agência & Escopo \\
\hline $\begin{array}{l}\text { Autoridades Estaduais Responsáveis por Pesos e } \\
\text { Medidas }\end{array}$ & Rotulagem \\
\hline $\begin{array}{l}\text { Tóxicos na Embalagem da Casa de Compensação (TPCH } \\
\text { - Toxics in Packaging Clearinghouse) }\end{array}$ & Embalagem \\
\hline $\begin{array}{l}\text { Escritório da Califórnica de Avaliação de Perigo para a } \\
\text { Saúde Ambiental (OEHHA -California Office of } \\
\text { Environmental Health Hazard Assessment) }\end{array}$ & Produtos Químicos Tóxicos \\
\hline Código de Negócios e Profissões da Califórnia & Reivindicações de Fabricado nos EUA \\
\hline Departamento de Saúde da Califórnia & Cosméticos Seguros \\
\hline Departamento de Alimentos e Agricultura da Califórnia & Reivindicações orgânicas \\
\hline $\begin{array}{l}\text { Departamento de Regulamentação de Negócios e } \\
\text { Profissional da Flórida, Divisão de Fármacos, } \\
\text { Dispositivos e Cosméticos }\end{array}$ & Permissão do Fabricante \\
\hline Departamento de Saúde Pública de Illinois & Rotulagem de chumbo \\
\hline Departamento de Saúde e Hospitais de Louisiana & Registro e rotulagem de cosmético \\
\hline Departamento de Saúde da Minnesota & Formaldeído, triclosan \\
\hline
\end{tabular}

\section{Embalagem e Rotulagem}

\section{Leis e Regulamentações Uniformes (UPLR - Uniform Laws and Regulations)}

As Leis e Regulamentações Uniformes nas áreas de Metrologia Legal e Qualidade de Combustível para Motores, NIST Handbook 130, Regulamentação de Embalagem e Rotulagem Uniformes (UPLR Uniform Packaging and Labeling Regulation), foram adotadas na lei de 45 dos 50 estados americanos. O propósito dessas Regulamentações é fornecer informações precisas e adequadas quanto à identidade e quantidade do conteúdo das embalagens de modo que os compradores possam fazer comparações de preço e quantidade. 
A UPLR requer que a embalagem destinada para o consumidor (excluídos os cosméticos como definido pela FDA; incluído sabonete) tenham um rótulo especificando a identidade da mercadoria; o nome e local de negócio do fabricante, embalador ou distribuido; e a quantidade líquida do conteúdo em termos de peso ou medição de massa ou contagem numérica em um local uniforme no painel de exibição principal.

\section{Tóxicos na Legislação de Embalagem}

Esta legislação foi originalmente preparada pelo Conselho de Redução de Fonte da Coalizão dos Governadores do Nordeste (CONEG - Coalition of Northeastern Governors) em 1989. Foi desenvolvida em um esforço para reduzir a quantidade de metais pesados em embalagens e componentes de embalagem que são vendidas ou distribuídas nos Estados Unidos. A lei é designada para eliminar o uso e a presença de mercúrio, chumbo, cádmio e cromo hexavalente na embalagem. A legislação foi adotada com sucesso pode dezenove estados.

Para informações mais detalhadas, consulte o artigo técnico Tóxicos na Embalagem da Casa de Compensação: Folha Informativa em Embalagem

\section{Produtos Quínicos de Interesse}

Vários estados, incluindo Oregon, Washington, Vermont, Minnesota e Maine, requerem que os fabricantes que vendem produtos infantis que contêm um produto químico que esteja incluído na lista de produtos químicos de interesse do estado avisem o estado antes da venda naquele estado. Em alguns casos, o fabricante precisa remover ou substituir o produto químico. As listas estão sujeitas a alterações, incluindo a adição de novos produtos químicos ou a remoção de produtos químicos listados, de modo que os fabricantes são incentivados a consultar a regra de relatório do estado.

\section{Compostos Orgânicos Voláteis}

Vários estados, incluindo Califórnia, Illinois, Indiana, Michigan, Ohio e Utah emitiram limitações de Compostos Orgânicos Voláteis (VOC - Volatile Organic Compounds) em produtos destinados ao consumidor. Os produtos impactados variam de estado para estado, mas podem incluir desodorantes, mousse para cabelos, brilho para cabelos, fixador para cabelos, produtos pessoais com fragrância, cremes e géis de barbear e tonalizante temporário para cabelos.

\section{Estado da Califórnia}

\section{Chumbo e outras Substâncias Tóxicas}

A Califórnia regula o chumbo e várias outras substâncias e produtos químicos através da Lei sobre Água Potável e Substâncias Tóxicas de 1986, mais popularmente conhecida como Proposição 65 ou Prop 65 (Código de Saúde e Segurança da Califórnia. Seção 25249.6, et seq.) Essas resoluções fornecem diretrizes para limites sugeridos. A Lista de Substâncias Perigosas da Prop 65 é mantida e atualizada quando novos produtos químicos são identificados. 
A seguinte linguagem de aviso é requerida nos produtos vendidos na Califórnia se contiverem produtos químicos na lista da Proposição 65 e se o nível de exposição a produtos químicos restritos não está dentro dos limites de segurança definidos:

AVISO: Este produto contém produtos químicos conhecidos no Estado da Califórnia por causarem câncer e defeito de nascença ou outros danos reprodutivos.

Em 30 de agosto de 2016, o Escritório de Direito Administrativo aprovou emendas à Prop 65 - Artigo 6: Avisos claros e razoáveis, que modificaram o aviso que precisa ser usado no rótulo. Isto entrará em vigor em 30 de agosto de 2018, mas os novos avisos podem ser usados antes desta data.

Os negócios que expoem pessoas aos produtos químicios listados precisam fornecer um aviso no produto. $\mathrm{O}$ aviso dado precisa ser "claro e razoável" e precisa:

- comunicar claramente que o produto químico é conhecido por causar câncer e/ou defeitos de nascença ou outros danos reprodutivos; e

- alcançar a pessoa de forma eficaz antes da exposição

- O aviso de exposição ao produto destinado ao consumidor precisa ser proeminentemente apresentado em um rótulo, na rotulagem ou um sinal colocado de tal forma que seja provável que seja lido e entendido por uma pessoa comum, sob uso comum.

O aviso do produto precisa conter os seguintes elementos:

- um simbolo de um ponto de exclamação preto em um triângulo equilátero amarelo com um contorno em preto e negrito colocado à esquerda da palavra AVISO em um tamanho não menor que a altura da palavra AVISO.

- A palavra AVISO em letras maiúsculas e em negrito

- A declaração do aviso

- Para exposições aos carcinógenos listados, as palavras: "Este produto pode expô-lo a produtos químicos incluindo [nome de um ou mais produtos químicos], que é [são] conhecido[s] como causadores de câncer pelo Estado da Califórnia. Para mais informações visite www.P65Warnings.ca.gov.

- Os avisos no produto devem declarar: "Câncer - www.P65Warnings.ca.gov."

- Para exposições às substâncias tóxicas para a reprodução, as palavras: "Este produto pode expô-lo a produtos químicos incluindo [nome de um ou mais produtos químicos], que é [são] conhecido[s] como causadores de defeitos de nascença ou outros danos reprodutivos pelo Estado da Califórnia. Para mais informações visite www.P65Warnings.ca.gov."

- Os avisos no produto devem declarar: "Dano reprodutivo www.P65Warnings.ca.gov"

- Para exposições a ambas, as substâncias carcinogênicas e tóxicas para a reprodução, as palavras: "Este produto pode expô-lo a produtos químicos incluindo [nome de um ou mais produtos químicos], que é [são] conhecido[s] como causadores de câncer e [nome de um ou mais produtos químicos], que é [são] conhecido[s] causadores de defeitos de nascença ou outros danos reprodutivos pelo Estado da Califórnia. Para mais informações visite www.P65Warnings.ca.gov." 
- Os avisos no produto devem declarar: "Câncer e Dano Reprodutivo www.P65Warnings.ca.gov"

- Para exposições a um produto químico que está listado como carcinogênio e tóxico para a reprodução, as palavras: "Este produto pode expô-lo a produtos químicos incluindo [nome de um ou mais produtos químicos], que é [são] conhecido[s] como causadores de câncer e defeitos de nascença ou outros danos reprodutivos pelo Estado da Califórnia. Para mais informações visite www.P65Warnings.ca.gov."

- Aviso no produto: "Câncer e Dano Reprodutivo - www.P65Warnings.ca.gov"

Para mais informações oficiais detalhadas da Califórnia sobre a Proposição 65, consulte: Escritório de Avaliação de Perigo para a Saúde Ambiental (OEHHA), Proposição 65 em Linguagem Simples, Prop65 News de Prop 65 News, Aviso de Adoção do Artigo 6: Avisos Claros e Razoáveis

\section{Lei de Cosméticos Seguros da Califórnia}

A Lei de Cosméticos Seguros da Califórnia requer para todos os produtos cosméticos vendidos na Califórnia que o fabricante, embalador e/ou distribuidor nomeado no rótulo do produto forneça ao Programa de Cosméticos Seguros da Califórnia (CSCP) uma lista de todos os produtos cosméticos que contenham quaisquer ingredientes conhecidos ou suspeitos de causar câncer ou dano de desenvolvimento ou outro dano reprodutivo. Vestígios de contaminantes não precisam ser reportados. Ingredientes normais de cosmético que não requerem relato são dióxido de titânio, palmitato de retinila e Preto 2. A Lista de Ingredientes a Serem Relatados pode ser consultada para determinar produtos a serem relatados.

\section{Para Informações mais Detalhadas, consulte o Departamento de Saúde da Califórnia:} Programa de Cosméticos Seguros da Califórnia

\section{Cosméticos Orgânicos}

A Lei de Produtos Orgânicos da Califórnia de 2003 (COPA - California Organic Products Act) requer que os produtos cosméticos vendidos, rotulados ou representados como orgânicos ou produzidos com ingredientes orgânicos precisam conter pelo menos 70 por cento de ingredientes produzidos organicamente.

Produtos cosméticos com múltiplos ingredientes vendidos como orgânicos que contenham menos de 70 por cento de ingredientes produzidos organicamente apenas podem identificar o conteúdo orgânico através de um dos seguintes métodos.

- Identificar cada ingrediente produzido organicamente na declaração de ingredientes com a palavra orgânico ou com um asterisco ou outra marca de referência que seja definida abaixo da declaração de ingredientes para indicar que o ingrediente é organicamente produzido.

- Apresentar a porcentagem de conteúdo orgânico do produto no painel de informação se os ingredientes organicamente produzidos forem identificados na declaração de ingredientes.

A Regulamentação também estipula a manutenção de registros e requisitos de registro. 
Em 2012, o Juiz Beeler da Corte Distrital Americana para o Distrito Norte da Califórnia ordenou que as Disposições da COPA relacionadas às reivindicações orgânicas para cosméticos não sejam adaptadas pela Lei de Produtos Alimentícios Orgânicos de 1990 (OFPA - Organic Foods Product Act) porque ela não barra as disposições de rotulagem da lei estadual que não estão em conflito com as disposições da OFPA e do Programa Nacional de Alimentos Orgânicos.

\section{Fabricado nos EUA}

A Califórnia também tem leis que governam quando uma reivindicação de "Fabricado nos EUA" puder ser feita para um produto. Apesar de a lei da Califórnia ser, por um tempo, a mais rigorosa, uma lei recente relaxou a rigorosa lei de "Fabricado nos EUA" da Califórnia. De acordo com a lei revista "Fabricado nos EUA", "Fabricado na América", "EUA" ou rótulos similares são permitidos mesmo se o produto tiver alguns componentes estrangeiros. A rotulagem é permitida se qualquer componente ou peça estrangeiro não constituir mais de 5 por cento do valor final de varejo do produto ou qualquer componente ou peça estrangeiro não constituir mais de 10 por cento do valor final de varejo do produto E o fabricante puder demonstrar que esses componentes não podem ser obtidos ou produzidos domesticamente.

\section{Estado da Flórida}

\section{Permissão do Fabricante de Produto Cosmético}

Os cosméticos vendidos na Flórida são regulados pela Divisão de Fármacos, Dispositivos e Cosméticos. Qualquer pessoa que fabrique, embale, re-embale, rotule ou re-rotule um fármaco, dispositivo ou cosmético neste estado precisa registrar tal fármaco, dispositivo ou cosmético a cada dois anos. Adicionalmente, é requerido uma permissão de fabricação de cosmético para qualquer pessoa que fabrique ou re-embale cosméticos neste estado. Uma pessoa que apenas rotule ou altere a rotulagem de um cosmético, mas que não abra o recipiente selado pelo fabricante do produto está isenta de obter uma permissão.

\section{Estado de Illinois}

\section{Chumbo}

Lei de Ordem Pública 097-0612, Lei de Prevenção de Envenenamento por Chumbo

A Lei torna ilegal vender ou doar qualquer substância contendo chumbo que possa ser usada pelo público em geral, a menos que contenha uma declaração de advertência conforme prescrito abaixo ou conforme prescrito por qualquer outra regulamentação federal. A declaração deverá estar localizada em um local proeminente no item ou na embalagem (16 CFR 1500.121) e incluirá pelo menos o seguinte:

\section{"AVISO: CONTÉM CHUMBO. PODE SER NOCIVO SE INGERIDO OU MASTIGADO.} PODE GERAR PÓ CONTENDO CHUMBO." 


\section{Estado de Louisiana}

\section{Leis de Cosméticos}

Os cosméticos embalados vendidos no estado precisam ser registrados junto à Unidade de Alimentos e Fármacos do Departamento de Saúde e Hospitais. A rotulagem está sujeita a revisão de conformidade como parte do registro.

Além disso, instalações envolvidas na fabricação, processamento, embalagem ou manutenção de cosméticos precisam ter uma permissão válida emitida pelo Escritório de Saúde Estadual através da Unidade de Alimentos e Fármacos do Escritório de Saúde Pública.

A Regulamentação de Cosméticos de Louisiana declara que a tintura para cabelos contendo alcatrão de tulha precisa ter o seguinte rótulo de advertência, bem como instruções adequadas para o teste preliminar:

Advertência - este produto contém ingredientes que podem causar irritação da pele em certas pessoas e um teste preliminar, de acordo com as indicações anexas, deve ser feito primeiramente. Este produto não pode ser usado para tingir cílios nem sobrancelhas, pois pode causar cegueira.

Apenas tinturas de origem animal ou vegetal e tais cores com carvão de tulha, conforme certificado pela FDA como seguras deverão se usadas, oferecidas para venda para uso ou distribuídas para uso em qualquer cosmético ou produto cosmético.

Nenhuma preparação cosmética ou de beleza contendo como ingrediente hormônios estrogênios, qualquer de seus derivados químicos ou qualquer produto químico sintético que possua propriedades similares às desses hormônios estrogênios pode ser fabricada, processada, embalada, vendida ou distribuída no estado de Louisiana a menos que seu rótulo contenha indicações adequadas para uso e seu rótulo contenha o número de unidades internacionais por onça de cada estrogênio ou ingrediente de estrogênio sintético.

\section{Estado de Minnesota}

\section{Formaldeído em Produtos Infantis}

Minnesota bane a venda de certos produtos concebidos para crianças menores de 8 anos que contenham formaldeído intencionalmente adicionado ou ingredientes que se degradem em formaldeído. Um produto infantil é definido como um produto basicamente projetado ou concebido por um fabricante para ser fisicamente aplicado ou introduzido no corpo da criança, incluindo qualquer artigo usado como componente de tal produto, excluindo alimentos, bebidas, suplemento alimentar, produto farmacêutico ou biológico, brinquedos infantis (cobertos pela ASTM F963) ou dispositivo médico. 


\section{Triclosan}

Os Estatutos de Minnesota Capítulo 145 Seção 145.945 banem o uso de triclosan em produtos que são usados pelos consumidores para desinfetar ou limpar mãos e corpo. As exceções a esta regra são produtos individuais que receberam aprovação da FDA para uso pelo consumidor. $O$ banimento entrou em vigor em 1 de janeiro de 2017.

\section{Visão Geral da EstrutuRa de PADRões Voluntários dos EUA}

O sistema americado de desenvolvimento de padrões é direcionado pelo setor privado. A maior parte dos padrões americanos são voluntários e desenvolvidos através de métodos de consenso que refletem as necessidades dos produtores e fabricantes, usuários e consumidores e do governo. $\mathrm{O}$ Instituto Nacional de Padrões Americano (ANSI - American National Standards Institute) (uma organização não governamental sem fins lucrativos) coordena as atividades da comunidade de desenvolvimento de padrões nos EUA. Há centenas de organizações de desenvolvimento de padrões nos Estados Unidos que são responsáveis pela padronização em muitas indústrias diferentes e setores de negócios. O Instituto Nacional de Padrões e Tecnologia (NIST - Nationa Institute of Standards and Technology), uma parte do Departamento de Comérico americano, é o laboratório de metrologia nacional dos Estados Unidos. O NIST fornece a infraestrutura de medição técnica para dar suporte ao comércio global e ao sistema de medição comercial. O NIST, através de seu Escritório de Coordenação de Padrões, aconselha e coordena a participação federal no estabelecimento de padrões.

\section{ORGANIZAÇÕes de DesenVolvimento de PADRões (SDOS)}

\section{ASTM International \\ 100 Barr Harbor Drive \\ P.O. Box C700 \\ West Conshohocken, PA 19428-2959 EUA \\ Telefone: 1.610.832.9500 \\ Lista de Pessoal}

A ASTM Internacional (ASTM) desenvolve e mantém padrões de consenso e métodos de teste relacionados a uma variedade de produtos.

Exemplos de padrões da ASTM que podem ser usados para testar produtos cosméticos incluem:

\begin{tabular}{|l|l|}
\hline ASTM E640 & Método de Teste de Padrão para Conservantes em Cosméticos Contendo Água \\
\hline ASTM E2361 & Guia de Padrão para Teste de Produtos sem Enxágue Usando Método In-Situ \\
\hline ASTM F719 & Prática de Padrão para Teste de Biomateriais em Coelhos para Irritação Primária da Pele \\
\hline $\begin{array}{l}\text { WK30352 } \\
\text { (Item de Trabalho) }\end{array}$ & $\begin{array}{l}\text { Novo Método de Teste para Análise XRD de Talco Cosmético e Farmacêutico quanto a } \\
\text { Asbestos }\end{array}$ \\
\hline $\begin{array}{l}\text { WK30024 } \\
\text { (Item de Trabalho) }\end{array}$ & $\begin{array}{l}\text { Novo Método de Teste por Microscopia de Luz Polarizada (PLM - Polarized Light } \\
\text { Microscopy) de Talco Cosmético e Farmacêutico quanto a Asbestos }\end{array}$ \\
\hline
\end{tabular}




\section{Padrões UL}

Sede da UL

333 Pfingsten Road

Northbrook, IL 60062, EUA

Telefone: 1. 847.272.8800

Atendimento ao Consumidor: 1.877.854.3577

E-mail: CustomerExperienceCenter@ul.com

Os Padrões UL são usados para avaliar produtos, testar componentes, materiais, sistemas e desempenho e avaliar produtos ambientalmente sustentáveis, energias renováveis, produtos alimentícios e água, sistemas de reciclagem e outras tecnologias inovadoras. Os padrões UL são voluntários a menos que incorporados a título de referência em regulamentações ou códigos federais ou estaduais.

Nos EUA, a UL é credenciada pelo Instituto Nacional de Padrões Americano (ANSI) como designador auditado. No Canadá, a UL é credenciada pelo Conselho de Padrões do Canadá (SCC - Standards Council of Canada) como uma Organização de Desenvolvimento de Padrões (SDO - Standards Development Organization) nacionalmente reconhecida, capaz de desenvolver os Padrões Nacionais do Canadá (NSCs National Standards of Canada).

Os Painéis Técnicos de Padrões (STPs - Standards Technical Panels) servem como uma entidade de consenso para os Padrões Nacionais Americanos (ANS - American National Standards) e National Standards of Canada (NSC - National Standards of Canada).

Os Padrões UL fazem parcerias com as entidades de padrões nacionais em países de todo o mundo.

Exemplos de Padrões UL aplicáveis incluem:

\begin{tabular}{|l|l|}
\hline UL 2845 & Padrão para Sustentabilidade para Produtos de Cuidados Pessoais \\
\hline UL 2932A & $\begin{array}{l}\text { Padrão para Processo de Avaliação de Risco para a Saúde Humana para Produtos } \\
\text { para Cuidados Pessoais e Cosméticos }\end{array}$ \\
\hline
\end{tabular}

\section{Convenção da Farmacopeia dos EUA (USP - U.S. Pharmacopeia)}

12601 Twinbrook Parkway

Rockville, MD 20852-1790, EUA

Telefone: 1.800 .227 .8772

A USP é uma organização científica sem fins lucrativos que estabelece padrões para identidade, potência, qualidade e pureza para remédios, alimentos e suplementos alimentícios. Embora não especificamente criados para cosméticos, esses padrões podem ser usados para demonstrar a segurança do produto.

Os padrões USP incluem:

\begin{tabular}{|l|l|}
\hline$<51>$ & Teste de Eficácia Antimicrobiana \\
\hline$<61>$ & Exame Microbiano de Produtos Não Estéreis: Testes de Enumeração Micorbianas \\
\hline$<62>$ & Exame Microbiano de Produtos Não Estéreis: Testes para Micro-organismos Específicos \\
\hline
\end{tabular}




\section{Organização de Padrões Internacionais (ISO - International Standards \\ Organization)}

Secretariado SO Central

BIBC II

Chemin de Blandonnet 8

CP 401

1214 Vernier, Genebra, Suíça

Telefone: 41227490111

E-mail: central@iso.org

A ISO é uma organização internacional não governamental independente tendo 163 organismos de padrões nacionais como membros. Através de seus membros, ela reúne especialistas para compartilhar conhecimento e desenvolver Padrões Internacionais relevantes para o mercado basedos em consenso.

Os padrões ISO relacionados a cosméticos incluem os seguintes:

\begin{tabular}{|l|l|}
\hline ISO 10130 & $\begin{array}{l}\text { Cosméticos - Métodos analíticos - Nitrosaminas Deteç̧ão e } \\
\text { determinação de N-nitrosodietanolamina (NDELA) em cosméticos } \\
\text { por HPLC, fotólise pós-coluna e derivatização }\end{array}$ \\
\hline ISO 11930 & $\begin{array}{l}\text { Cosméticos - Microbiologia - Avaliação da proteção antimicrobiana } \\
\text { de um produto cosmético }\end{array}$ \\
\hline ISO 12787 & $\begin{array}{l}\text { Cosméticos - Métodos analíticos - Critérios de validação para } \\
\text { resultados analíticos usando técnicas cromatográficas }\end{array}$ \\
\hline ISO/TR 14735 & $\begin{array}{l}\text { Cosméticos - Métodos analíticos - Nitrosaminas: Documento de } \\
\text { orientação técnica para minimizar e determinar N-nitrosaminas em } \\
\text { cosméticos }\end{array}$ \\
\hline ISO 15819 & $\begin{array}{l}\text { Cosméticos - Métodos analíticos - Nitrosaminas Deteç̧ão e } \\
\text { determinação de N-nitrosodietanolamina (NDELA) em cosméticos } \\
\text { por HPLC-MS-MS }\end{array}$ \\
\hline ISO 16128-1 & $\begin{array}{l}\text { Diretrizes sobre definições técnicas e critério para ingredientes e } \\
\text { produtos naturais e orgânicos - Parte 1: Definições para ingredientes }\end{array}$ \\
\hline ISO 16212 & Cosméticos - Microbiologia - Enumeração de levedura e mofo \\
\hline ISO/TR 17276 & $\begin{array}{l}\text { Cosméticos - Abordagem analítica para métodos de triagem e } \\
\text { quantificação para metais pesados em cosméticos }\end{array}$ \\
\hline ISO 17516 & Cosméticos - Microbiologia - Limites microbiológicos \\
\hline ISO 18415 & $\begin{array}{l}\text { Cosméticos - Microbiologia - Detecção de micro-organismos } \\
\text { específicos e não específicos }\end{array}$ \\
\hline ISO 18416 & Cosméticos - Microbiologia - Deteção de Candida albicans \\
\hline ISO/TR 19838 & $\begin{array}{l}\text { Microbiologia - Cosméticos - Diretrizes para aplicação dos padrões } \\
\text { ISO na Microbiologia Cosmética }\end{array}$ \\
\hline ISO 21148 & $\begin{array}{l}\text { Cosméticos - Microbiologia - Instruções gerais para exame } \\
\text { microbiológico }\end{array}$ \\
\hline
\end{tabular}




\begin{tabular}{|l|l|}
\hline ISO 21149 & $\begin{array}{l}\text { Cosméticos - Microbiologia - Enumeração e detecção de bactérias } \\
\text { mesofílicas aeróbicas }\end{array}$ \\
\hline ISO 21150 & Cosméticos - Microbiologia - Detecção de Escherichia coli \\
\hline ISO 22715 & Cosméticos - Embalagem e rotulagem \\
\hline ISO 22716 & $\begin{array}{l}\text { Cosméticos - Boas práticas de fabricação (BPF) - Diretrizes sobre } \\
\text { Boas Práticas de Fabricação }\end{array}$ \\
\hline ISO 22717 & Cosméticos - Microbiologia - Detecção de Pseudomonas aeruginosa \\
\hline ISO 22718 & Cosméticos - Microbiologia - Deteç̧ão de Staphylococcus aureus \\
\hline ISO 24442 & $\begin{array}{l}\text { Cosméticos - Métodos de teste de proteção solar - Determinação in } \\
\text { vivo de proteção UVA de filtro solar }\end{array}$ \\
\hline ISO 24443 & Determinação de fotoproteção UVA de filtro solar in vitro \\
\hline ISO 24444 & $\begin{array}{l}\text { Cosméticos - Métodos de teste de proteção solar - Determinação in } \\
\text { vivo de fator de proteção solar (FPS) }\end{array}$ \\
\hline
\end{tabular}

\section{ENTIDADES DE TESTE E CERTIFICAÇÃO}

\section{Laboratórios de Teste}

Vários laboratóriso testam cosméticos quanto aos padrões da indústria reconhecidos; alguns podem ser credenciados.

\section{Procedimentos de Teste}

Os cosméticos não devem conter nenhum organismo danoso. A FDA oferece um conjunto de procedimentos chamado Manual Analítico Bacteriológico (BAM - Bacteriological Analytical Manual) para a detecção de patógenos em alimentos e produtos cosméticos, como o Capítulo 23, Métodos Microbiológicos para Cosméticos.

\section{Certificação}

\section{Produtos Sujeitos às Regras de Segurança de Produto Destinado ao Consumidor}

Seção 102 da CPSIA requer que todo fabricante ou importador de todos os produtos destinados ao consumidor que estão sujeitos a uma regra de segurança de produto destinado ao consumidor executada pela CPSC emita um certificado declarando que o produto cumpre com o padrão, regulação ou banimento aplicável. O certificado precisa acompanhar o produto e ser fornecido ao varejista ou distribuidor. A Seção 102 também requer que os fabricantes ou importadores de produtos infantis (menores de 12 anos) certifiquem que os produtos cumprem com todos os padrões de segurança de produto relevantes através da emissão do certificado de produto infantil apoiado por testes realizados por um laboratório de teste terceirizado aceito pela CPSC. 


\title{
Aditivos de Cor
}

Os aditivos de cor para uso em cosméticos precisam satisfazer a aprovação rigorosa da FDA. Além disso, precisam satisfazer os requisitos de identidade, especificações, usos e restrições e os aditivos de cor que podem ser certificados (e seus "excessos") precisam ser certificados pela FDA. Os aditivos de cor chamados "alcatrão de tulha" (ou seja, aditivos de cor orgânicos sintéticos) estão sujeitos a certificação de lote.

Para mais informações, consulte o item da FDA:

Aditivos de Cor e Cosméticos

Aditivos de Cor com Uso Permitido em Cosméticos

\section{NSF International}

P.O. Box 130140

789 N. Dixboro Road

Ann Arbor, MI 48105, EUA

Telefone: 1.734 .769 .8010

E-mail: info@nsf.org

A NSF é uma organização credenciada independente que desenvolve padrões e testes e certifica produtos e sistemas. Fornece auditoria, educação e soluções de gerenciamento de risco para saúde pública e meio ambiente. Os produtos que cumprem com todos os requisitos de padrão podem apresentar uma marca de certificação NSF.

\section{Para mais informações, consulte o item da NSF:}

Cosméticos

Programa de Cosméticos e Cuidados Pessoais

\author{
$\underline{\text { UL Registrar LLC }}$ \\ 4 Fork Street, 1st Floor \\ Mount Pocono, PA 18344 EUA \\ Telefone: 1.800 .903 .5660 \\ E-mail: ULRinfo@ul.com
}

A UL Registrar LLC é um organismo de avaliação de conformidade credenciada pela ANSI e ANAB e fornece avaliações de fabricação e processo terceirizadas credenciadas e independentes em comparação a um padrão definido que visa minimizar o risco da cadeia de suprimento, a ajudar a proteger o valor da marca e a promover a segurança do consumidor e do produto. A UL Registrar é um Esquema de Certificação Credenciado pela ANSI para a ISO 22716 e fornece serviços de verificação para as Boas Práticas de Fabricação (BPF) de fabricantes de cosméticos requeridas na ISO 22716.

Para mais informações, consulte o item da UL:

Documento Técnico da Certificação da ISO 22716

Programa de Certificação de Cuidados Pessoais e Cosmético 


\section{AGÊNCIAS GOVERNAMENTAIS AMERICANAS RELEVANTES}

Comissão de Segurança de Produtos Destinados ao Consumidor (CPSC)

4330 East West Highway

Bethesda, MD 20814 EUA

Telefone: 1.301.504.7923

E-mail: http://www.cpsc.gov/About-CPSC/Contact-Information/Contact-Specific-Offices-and-PublicInformation/Information-Center/

Escritório da CPSC

Escritório de Programas Internacionais e Assuntos Intergovernamentais

Escritório de Conformindade e Operações em Campo

Vice-Diretor

Escritório de Vigilância de Importação
Telefone

1.301.504.7071

1.301.504.7915

1.301.504.7520

1.301.504.7677

\section{Alfândega e Proteção de Fronteiras Americana (CBP)}

1300 Pennsylvania Avenue, NW

Washington, D.C. 20229 EUA

Telefone: 1.703 .526 .4200

Lista de Contatos

Para mais informações, consulte o item da CBP:

Importando cosméticos, sabonete, loção, xampu, instrumentos médicos e dentais para revenda/propósitos comerciais

\section{Agência de Proteção Ambiental (EPA - Environmental Protection Agency)}

1200 Pennsylvania Avenue, NW

Washington, DC 20460

Telefone: 1.202.272.0167

Lista de Contatos

\section{Comissão Federal de Comércio (FTC)}

600 Pennsylvania Avenue, NW

Washington, DC 20580

Telefone: 1.202.326.2222

Lista de Contatos

\section{Administração de Alimentos e Fármacos (FDA)}

10903 New Hampshire Ave

Silver Spring, MD 20993-0002

Telefone: 1.888.INFO.FDA

Página de Consulta 
Nos EUA, a indústria de cosméticos faz uma contribuição importante para o desenvolvimento e fornecimento de recursos para as empresas que fabricam produtos cosméticos e ingredientes que são seguros para os consumidores e para o meio ambiente. A orientação fornece recursos para informações adicionais para as empresas americanas sobrre como podem cumprir com os requisitos do governo americano, bem como promover a liderança da indústria nessas questões. Frequentemente, estas iniciativas são realizadas com consulta ao governo americano e outros envolvidos, mas isto não indica que esses recursos são endossados pelo governo.

\section{Associações Comerciais da Indústria}

Uma lista das associações comerciais da indústria pode ser encontrada na página da web da FDA: Associações Comerciais e Profissionais

\section{Revisão de Ingrediente Cosmético (CIR - Cosmetic Ingredient Review)}

1620 L St. N.W., Suite 1200

Washington D. C. 20036

Fone: (202) 331-0651

Fax: (202) 331-0088

E-mail: cirinfo@cir-safety.org

Site: www.cir-safety.org

A Revisão de Ingrediente Cosmético (CIR) foi estabelecida em 1976 pela associação comercial da indústria (na época, Associação de Cosméticos, Artigos de Higiene Pessoal e Fragrância, agora Conselho de Produtos de Cuidados Pessoais), com o apoio da Administração de Alimentos e Fármacos americana e da Federação de Consumidores da América. A CIR estuda compostos químicos individuais à medida que são usados em produtos cosméticos e faz recomendações para o setor sobre a segurança e uso desses compostos com base em uma revisão da literatura e dados científicos disponiveis.

Embora tenha sido fundada pelo Conselho, a CIR e o processo de revisão são independentes do Conselho e do setor de cosméticos. A CIR opera sob um conjunto de procedimentos. A política e direcionamento gerais são dados por um Comitê de Direção composto por nove membros. O Painel é composto por três dermatologistas, um dos quais é o presidente, dois químicos, quatro farmacologistas/toxicologistas. As ligações não votantes do Painel incluem um representante de cada um do Conselho de Cuidados Pessoais, da FDA Americana e da Federação de Consumidores da América.

A FDA observa as atividades da CIR, como uma ligação não votante, e pode usar as descobertas da CIR em suas próprias revisões de segurança de ingredientes cosméticos. 
Nomenclatura Internacional para Ingredientes Cosméticos (INCl - International Nomenclature for Cosmetics Ingredients)

c/o Personal Care Products Council

1620 L St. N.W., Suite 1200

Washington D. C. 20036

Fone: (202) 331-0651

Fax: (202) 331-0088

E-mail: inci@personalcare.org

Site: www.personalcarecouncil.org/public/what-inci

O Comitê de Nomenclatura de Ingredientes Cosméticos Internacional (INC - International Ingredient Nomenclature Committee), patrociando pelo Conselho de Produtos de Cuidados Pessoais, designa o sistema uniforme de nomes para ingredientes cosméticos que são usados em todo o mundo. Nos Estados Unidos, e em muitos outros países, os nomes do $\mathrm{INCl}$ servem de referência em regulamentações para rotulagem de ingredientes de produtos cosméticos. Como parte do processo para desenvolver os nomes $\mathrm{INCl}$, o INC supervisiona o desenvolvimento contínuo do sistema de nomenclatura do INCl e assegura a integridade das informações relacionadas aos nomes INCI que são publicados no International Cosmetic Ingredient and Handbook. Esta nomenclatura sistemática também serve para mover o setor de cosméticos doméstico e os países que usam o INCl em direção à harmonização dos nomes de ingredientes.

\section{Para Informações Adicionais, consulte as publicações do Conselhor de Produtos de Cuidados Pessoais:}

\section{Diretrizes para a Indústria: $O$ Teste de Estabilidade de Produtos Cosméticos}

Esta diretriz pretende fornecer um recurso para os fabricantes no desenvolvimento de um programa de teste de estabilidade. Ilustra o pensamento atual do setor sobre este tópico e identifica um pacote de dados de estabilidade que seja aceitável para comercialização. A diretirz delineia os parâmetros chave da estabilidade para produtos cosméticos, mas deixa flexibilidade suficiente para englobar a variedade de situações práticas diferentes que podem ser encontradadas devido a considerações científicas específicas e características dos materiais sendo avaliados. Abordagens alternativas ou variações dessas diretrizes podem ser usadas (por exemplo, onde houver justificativa científica ou para satisfazer requisitos dentro de uma jurisdição em particular) desde que a intenção básica do programa seja mantida.

\section{Manual Internacional de Cor, 4a Edição}

A quarta edição do Manual Internacional de Cor auxilia o pessoal internacional, de regulamentação e técnico na escolha de uma paleta de cores para criar uma faixa mais ampla de produtos cosméticos ao mesmo tempo que satifazem os requisitos nacionais e analisam as regulamentações de aditivo de cor para mais de 100 países e compara-as com as regulamentações dos EUA, da União Europeia e do Japão.

\section{Manual de Rotulagem, 9a Edição}

Manual do Conselho de Produtos de Cuidados Pessoais: Um Guia para Rotulagem e Propaganda de Cosméticos e Fármacos OTC, Nona Edição, apresenta uma visão profunda das regulamentações americanas para rotular cosméticos, fármacos de venda livre e produtos profissionais. Fornece informações atualizadas e melhoradas sobre os requisitos para a rotulagem de cosméticos de acordo com a FPLA e Lei FD\&C 


\section{Diretrizes de Garantia da Qualidade}

As Diretrizes de Garantia da Qualidade fornecem abordagens que os fabricantes de cosméticos podem usar para estabelecer suas boas práticas de fabricação e programas de garantia da qualidade. As Diretrizes fornecem uma estrutura para estabelecer sistemas e procedimentos que são necessários para atingir um alto nível de qualidade do produto e evitar problemas que poderiam afetar adversamente o produto. O Padrão ISO 22716 está incluído como documento de referência anexado a essas Diretrizes.

\section{Diretrizes de Avaliação de Segurança}

As Diretrizes de Avaliação de Segurança fornecem aos fabricantes de produtos cosméticos, artigos de higiene pessoal e fragrâncias orientação no uso de teste de segurança pré-clínico e clínico como meio de substanciar a segurança de ambos, ingrediente e produtos cosméticos acabados.

De outras associações americanas do setor:

Fabricantes e Distribuidores de Cosméticos Independentes (ICMAD - Independent Cosmetic Manufacturers and Distributors)

21925 Field Parkway, Suite 205

Deer Park, IL 60010

Telefone: 1.800 .334 .2623

Formulário de Contato

A ICMAD é uma associação comercial sem fins lucrativos dedicada ao fornecimento de programas e serviços para aproximadamente 700 distribuidores, fabricantes e fornecedores de cosméticos.

Para informações adicionais, consulte as publicações da ICMAD:

Guia Completo da ICMAD para Regulamentações e Rotulagem de Cosméticos Americanas Este Guia contém informações sobre os requisitos de regulamentações e rotulagem, conforme estabelecido pela Administração de Alimentos e Fármacos americana no estatuto e regulamentação.

\section{Guia Prático da ICMAD para Venda de Cosméticos nos EUA}

Vender cosméticos nos Estados Unidos, o maior mercado de beleza no mundo, tem seu próprio conjunto de desafios únicos. Este guia ajuda as empresas a se familiarizarem com as regras nos EUA e tornar mais fácio introduzir novos produtos no mercado.

\section{Dados do Mercado de Cosméticos}

Conselho de Produtos de Cuidados Pessoais

Estudos Econômico e Contribuições Sociais do Setor 2016

Balcão de Produtos de Cuidados Pessoais e Cosméticos, Escritório da Indústria de Materiais, Departamento de Comércio Americano, Administração de Comércio Internacional Foco da Indústria: Produtos de Cuidados Pessoais e Cosméticos (Parte II) 
O Centro de Informações de Padrões NIST envida todos os esforços para fornecer informações precisas e completas. Vários dados como nomes, números de telefone, links para sites, etc., podem mudar antes da atualização. Sugestões sobre como melhorar este Guia e corrigir erros são bem-vindas. $O$ Centro de Informações de Padrões fornece estas informações "COMO ESTÃO". O NIST e o Centro de Informações de Padrões NÃO FORNECEM GARANTIA DE QUALQUER TIPO, incluindo NENHUMA GARANTIA DE COMERCIABILIDADE OU ADEQUAÇÃO PARA UM PROPÓSITO ESPECÍFICO. O NIST não fornece garantias ou representações quanto à correção, precisão, totalidade ou confiabilidade das informações das Folhas Informativas. Como condição para uso dos Guias, você explicitamente libera o NIST/Centro de Informações de Padrões de toda e qualquer responsabilidade por qualquer dano, de qualquer tipo, que possa resultar de erros ou omissões no Guia ou em outros dados. Alguns dos documentos aqui mencionados indicam informações criadas e mantidas por outras organizações. $O$ Centro de Informações de Padrões não controla e não pode garantir a relevância, oportunidade ou precisão desses materiais.

Maio de 2017

Preparado pelo Centro de Informações de Padrões Departamento de Coordenação de Padrões (SCO) National Institute of Standards and Technology (NIST) standardsinfo@nist.gov 